\title{
Sugar-Induced Signal Transduction In Plants
}

\author{
Sjef Smeekens \\ Department of Molecular Plant Physiology, University of Utrecht, Padualaan 8, $3584 \mathrm{CH}$ \\ Utrecht, The Netherlands; e-mail: j.c.m.smeekens@bio.uu.nl
}

Key Words hexose sensing, sucrose sensing, hexokinase, phytohormones, Arabidopsis, signal transduction

- Abstract Sugars have important signaling functions throughout all stages of the plant's life cycle. This review presents our current understanding of the different mechanisms of sugar sensing and sugar-induced signal transduction, including the experimental approaches used. In plants separate sensing systems are present for hexose and sucrose. Hexokinase-dependent and -independent hexose sensing systems can further be distinguished. There has been progress in understanding the signal transduction cascade by analyzing the function of the SNF1 kinase complex and the regulatory PRL1 protein. The role of sugar signaling in seed development and in seed germination is discussed, especially with respect to the various mechanisms by which sugar signaling controls gene expression. Finally, recent literature on interacting signal transduction cascades is discussed, with particular emphasis on the ethylene and ABA signal transduction pathways.

\section{CONTENTS}

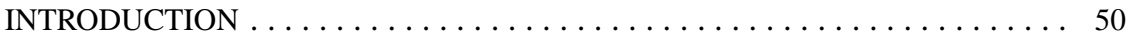

APPROACHES TO STUDYING SUGAR SENSING AND SIGNALING $\ldots \ldots \ldots$. . 51

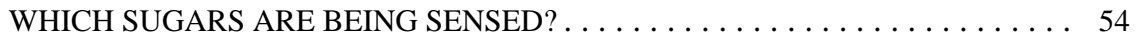

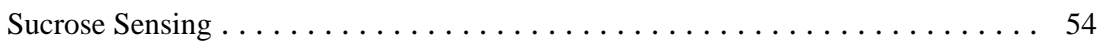

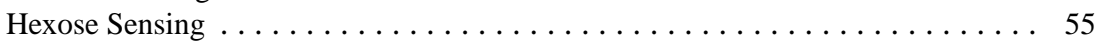

THE SIGNAL TRANSDUCTION CASCADE . . . . . . . . . . . . 58

Protein Kinases, Protein Phosphatases, $\mathrm{Ca}^{2+}$, and Calmodulin . . . . . . . 58

The SNF1 Kinase Complex . . . . . . . . . . . . . . . . . . . . . . . 60

PRL1, A SNF1 Kinase Complex Interacting Protein . . . . . . . . . . 63

Nuclear Processes . . . . . . . . . . . . . . . . . . . . . . . 64

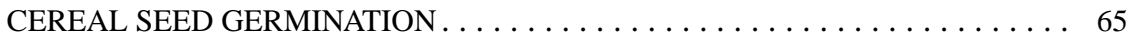

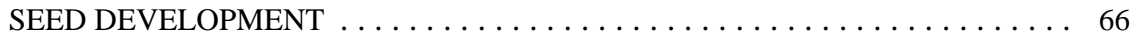

INTERACTING SIGNALING PATHWAYS $\ldots \ldots \ldots \ldots \ldots \ldots \ldots \ldots \ldots \ldots$

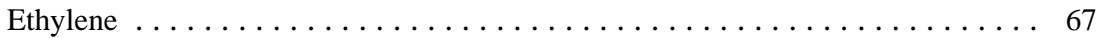

Abscisic Acid and Gibberellic Acid . . . . . . . . . . . . . . . . 67

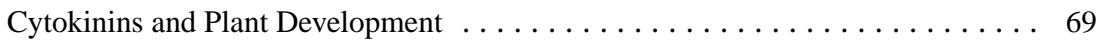




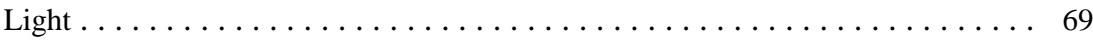

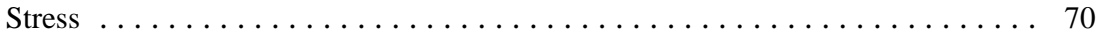

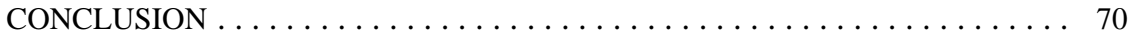

\section{INTRODUCTION}

Sugars such as sucrose, glucose, and fructose have an essential function in plant metabolism. These sugars are important for intermediary and respiratory metabolism and are the substrate for synthesizing complex carbohydrates such as starch and cellulose. Moreover, sugars provide the building blocks for amino acid and fatty acid biosynthesis and essentially all other compounds present in plants. These metabolic processes have long been studied in depth but another aspect of plant sugar biology has recently become the focus of intense research efforts: the signaling function of sugars. Sugars as such can signal alterations in gene expression similar to the concepts developed for hormones. Whereas hormones are purposebuilt molecules that are functional in the nano- to micromolar range, sugars take part in intermediary metabolism and are present in the millimolar range. Sugar sensing can be defined as the interaction between a sugar molecule and a sensor protein in such a way that a signal is generated. This signal then initiates signal transduction cascades that result in cellular responses such as altered gene expression and enzymatic activities. The metabolic and signaling functions of sugars are not always easy to separate but in many cases, convincing evidence for a signaling function has been obtained. Questions addressed in sugar sensing and signaling are similar to those of other signal transduction cascades. These relate to which sugars are being sensed, their interaction with sensor molecules, the molecular nature and cellular location of these sensors, the transduction of the signal and, finally, the way in which gene expression, enzymatic activities, or other cellular processes are altered.

Sugars as signaling compounds have profound effects in all stages of the plant's life cycle from germination and vegetative growth to reproductive development and seed formation. There has been extensive research effort in bacteria, yeast, and animal systems to understand sugar sensing in molecular detail; the yeast glucose repression system in particular has provided a wealth of information $(18,40,79)$. This information is important for other eukaryotes as well. Sugar sensing in yeast is by definition a cell-autonomous process, a characterization most likely true for plant cells as well. However, in multicellular plants with specialized metabolic organs and metabolite transport systems, integrative responses to plant sugar status are needed.

Several excellent reviews on sugar sensing have recently appeared $(47,74,88$, $132,149,150)$. The review by Koch (88) presented and discussed an extensive list of sugar-regulated genes. This review aims to provide an update on recent literature and an integrated view of sugar signaling in plants. First, the experimental approaches to studying sugar signaling are introduced, followed by a discussion 
on the different aspects of known sugar sensing mechanisms and sugar mediated signal transduction. In the final part, sugar signaling and its integration with other plant signaling and developmental pathways are discussed.

\section{APPROACHES TO STUDYING SUGAR SENSING AND SIGNALING}

The various strategies for studying sugar signaling can be divided into genetic, molecular, biochemical, and physiological approaches. The creative combination of these methodologies has been productive in many fields and is also used successfully to study sugar-signaling pathways in plants.

Mutants are important tools to analyze the physiological function of complex sensing and signaling systems. Moreover, mutants allow the study of functional interactions between genes. Importantly, in several plant systems, the technology is now available to clone the relevant genes and study their function. Arabidopsis is being used extensively in sugar sensing research for mutant identification, and several laboratories have established different mutant identification protocols (Table 1). Several groups are using reporter-based screening protocols in which promoters of sugar-induced or sugar-repressed genes are linked to reporters like $\beta$-glucuronidase $(G U S, i u d A)$ or luciferase $(L U C)$ genes. These constructs are introduced into plants and used as tools to select sugar-unresponsive or sugar hyperresponsive mutants. The plastocyanin $(P C)$ gene of Arabidopsis can be repressed by sugars (31) and in seedlings carrying a $P C$-promoter luciferase reporter

TABLE 1 Strategies used by different groups to select for sugar sensing mutants in Arabidopsis

\begin{tabular}{|c|c|c|}
\hline & Screen & Reference \\
\hline \multicolumn{3}{|l|}{ Reduced sensitivity } \\
\hline cai carbohydrate insensitive & Low nitrogen, $100 \mathrm{mM}$ sucrose & $(15)$ \\
\hline glucose insensitive & Growth on $330 \mathrm{mM}$ glucose & $(188)$ \\
\hline lba low-level beta amylase & Amylase act., $175 \mathrm{mM}$ sucrose & $(104)$ \\
\hline mig mannose insens. germin. & Growth on $7.5 \mathrm{mM}$ mannose & (119) \\
\hline ram reduced beta amylase & pgm mutant on sucrose & $(32)$ \\
\hline reduced sugar response & $\operatorname{Pat}(B 33)-G U S, 90 \mathrm{mM}$ sucrose & $(101)$ \\
\hline sugar insensitive & $300 \mathrm{mM}$ sucrose or glucose & $(43)$ \\
\hline sucrose-uncoupled & $P C-L U C, 88 \mathrm{mM}$ sucrose & $(30)$ \\
\hline sucrose-insens. growth & Growth on $350 \mathrm{mM}$ sucrose & (119) \\
\hline \multicolumn{3}{|l|}{ Enhanced sensitivity } \\
\hline gss glucose super sensitive & Growth on $56 \mathrm{mM}$ glucose & $(119)$ \\
\hline sucrose super sensitive & Growth on $350 \mathrm{mM}$ sucrose & (119) \\
\hline hba high-level beta amylase & Amylase act., $175 \mathrm{mM}$ sucrose & $(105)$ \\
\hline prl1 pleiotopic regul. locus & Growth on $175 \mathrm{mM}$ sucrose & (111) \\
\hline
\end{tabular}


gene construct, luciferase activity is similarly repressed by sugars. Mutants defective in sucrose repression were identified on the basis of normal luminescence when grown on plates with $3 \%$ sucrose (30). Such sucrose uncoupled (sun) mutants show no or reduced sucrose repression of luminescence. In these mutants, endogenous $P C, C A B$, and $R B C S$ mRNA levels were similarly insensitive to sugar repression.

A similar strategy was used to select for mutants in sugar induction. The patatin class I (B33) promoter is induced by sugars, and signaling mutants were selected by using transgenic Arabidopsis plants harboring the Pat (B33)-iudA construct and a nondestructive GUS activity assay (101). In this way, reduced sugar response (rsr) mutants were identified in which sucrose-induced expression of patatin is perturbed. Genetic analysis suggests that one of these mutants, rsr4, is codominant (101) and likely encodes an activator, whereas most other sugar sensing mutants that were isolated are recessive and probably encode repressing functions.

The Arabidopsis $\beta$-amylase gene is induced by sugars, and mutants that display either an increased or a reduced sugar sensitivity have been isolated in amylase activity screens $(32,104,105)$. A mutant was identified showing elevated $\beta$-amylase expression (hbal, high level $\beta$-amylase) independent of the presence of sugars in the medium. Conversely, the low-level beta amylase (lba) mutants show reduced induction of $\beta$-amylase gene expression in response to sugars. Remarkably, the Arabidopsis Landsberg erecta (Ler) ecotype represents a natural lba mutant (105). A single recessive Ler locus, named $l b a 2$, reduced the sugar responsiveness of $\beta$-amylase gene expression. Sucrose-induced accumulation of anthocyanins is reduced in both $l b a l$ and $l b a 2$ mutants. Moreover, the expression of only a subset of sugar-regulated genes is affected in these mutants.

An equally effective mutant isolation strategy relies on the observation that Arabidopsis seedling development is arrested at high (6\%) glucose concentrations. Mutant seedlings that develop more or less normally in the presence of $6 \%$ glucose have been isolated and are named glucose insensitive (gin) (188). Other mutants with reduced sugar sensitivity are the carbohydrate insensitive (cai) mutants. Arabidopsis seedlings grown on a high-sucrose/low-nitrogen medium show enhanced sugar signaling due to increased intracellular sugar concentrations. Wildtype seedlings grown under these conditions accumulate high levels of anthocyanin and are low in chlorophyll. A number of cai mutants have been isolated that do not accumulate anthocyanin and that show higher levels of chlorophyll (15).

The glucose epimer mannose is phosphorylated by hexokinase (HXK) to mannose-6-phosphate (Figure 1), which only slowly enters glycolytic metabolism (87). In Arabidopsis mannose and also the glucose analog 2-deoxy glucose (2-dGlc) inhibit seed germination in a process that involves HXK signaling (121). Non-HXK substrates such as 3-O-methyl glucose (3-O-mGlc) and 6-deoxyglucose (6-dGlc) have no effect on germination, whereas the HXK inhibitor mannoheptulose relieves the mannose-induced block of germination. This mannose inhibition of germination can be reversed by the addition of metabolizable sugars. 


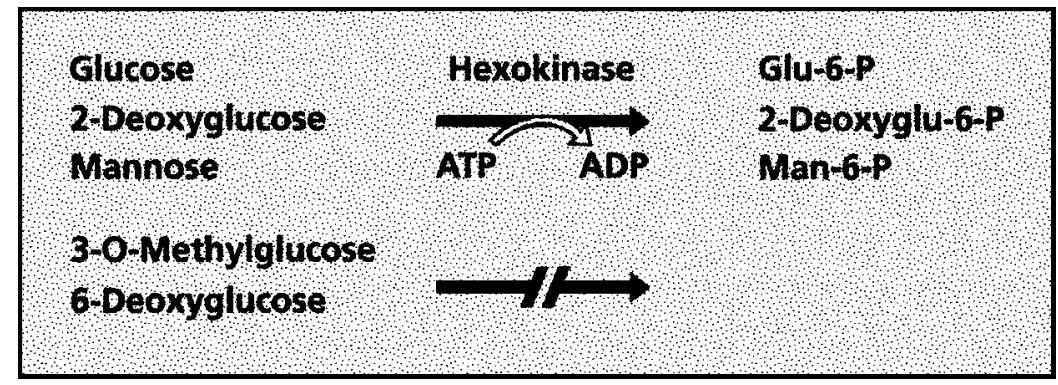

Figure 1 Mannose and 2-deoxy glucose are substrates for hexokinase. The resulting hexose phosphates can to some extent be further metabolized (87). 3-O-methyl glucose and 6-deoxy glucose are not metabolized by hexokinase.

Arabidopsis is an oilseed and during germination the lipids are converted to sucrose in a process that involves the glyoxylate cycle. Thus HXK signaling may inhibit mobilization of lipids and, possibly, other storage compounds as well, and in this way prevent germination (121). This observation was used to isolate mannoseinsensitive-germination (mig) mutants potentially defective in $\mathrm{HXK}$ activity or in HXK-induced signaling (119). Not surprisingly, several of the mutants isolated in a particular screen turned out to be mutants under other selective conditions as well, e.g. selected sun and cai mutants are mig and/or gin as well $(15,119)$. Other screening methods have been used (summarized in Table 1). Several of the mutant isolation protocols described allow for screening of T-DNA and transposon-tagged seed collections. This greatly accelerates the isolation of genes affected using PCR techniques, and a number of genes have been identified in this way. Notwithstanding their usefulness, these mutant selection approaches are rather crude and do not address the intricate complexities associated with sugar transport, sugar inter- and intracellular compartmentation, and plant development and differentiation. The challenge is to devise selective mutant identification procedures addressing these points.

In addition to the mutant isolation approach, genes have been cloned from several different plant species that are homologous to genes encoding known components of sugar sensing pathways in microorganisms, especially yeast (Saccharomyces cerevisiae). For example, yeast HXK is thought to play a central role as a sugar sensing molecule and plant HXK genes have been cloned and analyzed for their function in sugar sensing as well $(25,73)$. Also, plant genes have been isolated that encode homologues of the yeast heterotrimeric SNF1 kinase complex involved in derepression of glucose-repressed genes $(14,53,93)$. In addition, many pharmacological and other compounds are known that interfere with signal transduction steps, often with reasonable specificity. The effect of such compounds in inhibiting or promoting specific sugar responses is indicative of the involvement of specific intermediary steps in signaling. Thus, protein kinases, protein phosphatases, $\mathrm{Ca}^{2+}$, and calmodulin have been implicated in sugar signaling. 


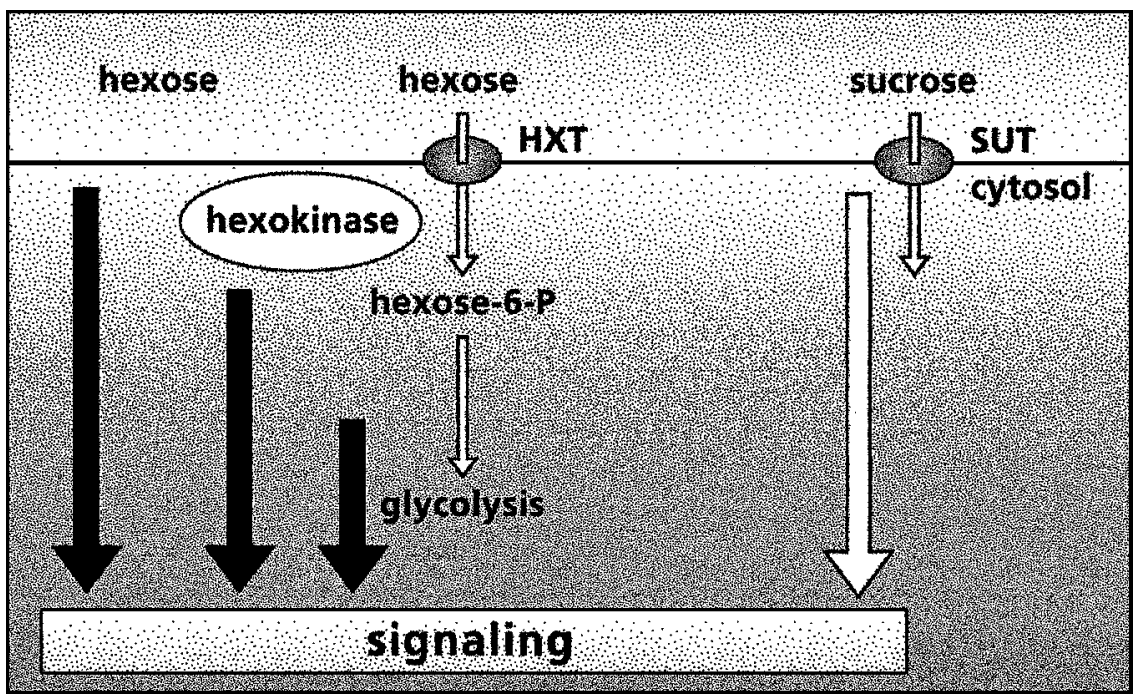

Figure 2 Sugar sensing mechanisms in plants. Hexose sensing can occur via separate hexokinaseindependent or hexokinase-dependent systems. Sucrose is sensed via a separate system.

\section{WHICH SUGARS ARE BEING SENSED?}

In principle, any neutral sugar or glycolytic intermediate could have a signaling function but so far this has only been shown for hexoses and sucrose (Figure 2). Next to sugars, the cellular energy status must have an important signaling function for the control of metabolism.

\section{Sucrose Sensing}

A signaling function for molecular sucrose was proposed in the past but only recently has experimental evidence for this role of sucrose become available. The problem is that sucrose can readily be hydrolyzed in glucose and fructose, and in the absence of specific non-hydrolyzable sucrose analogs, it is difficult to establish a direct function for the sucrose molecule. Sucrose-specific induction of gene expression has been reported for the patatin promoter and the phloem-specific rolC promoter, among others $(76,177,184)$. Glucose and fructose were less effective inducers. For these promoters, however, the function of sucrose as inducing agent has not been exhaustively investigated; sucrose is efficiently transported and hydrolyzed in plants and the resulting monosaccharides may be the signal. For example, the glucose analog 3-O-mGlc is an effective inducer of the patatin promoter (101).

Recently, an Arabidopsis basic leucine zipper gene, $A T B 2$, was described that is controlled by light and sucrose via transcriptional and translational control, respectively $(135,136)$. ATB2 expression is associated with newly established sink 
tissues. It is rapidly induced in funiculi upon fertilization of the ovules and is expressed in association with vascular tissue in developing leaves. Transcription of the gene is controlled by light through the DETI and COPI gene products. Remarkably, translation of the ATB2 mRNA is repressed specifically by sucrose at physiological concentrations. Other sugars and also combinations of glucose and fructose were ineffective in this repression. The ATB2 mRNA has a complex leader containing small open reading frames. Deletion of this leader abolishes sucrose repression, which shows that a sucrose-specific signal controls translation. Possibly, in this system it is the influx of sucrose into the cell that is being sensed rather than the actual cytosolic sucrose concentration, since Arabidopsis seedlings synthesize sucrose efficiently when glucose or fructose is added (31), although this sucrose apparently is not sensed. A signaling function for molecular sucrose was also suggested by experiments with excised sugar beet leaves (23). In this system, sucrose repressed mRNA levels and transport activity of the proton-sucrose symporter. Glucose and fructose had no effect on activity. In conclusion, these findings point to the presence of sucrose-specific sensing and signaling pathways in plants.

\section{Hexose Sensing}

Experimental evidence suggests the presence of at least two different systems for hexose sensing (Figure 2). One system senses hexose as such while the other requires substrate phosphorylation by a hexose kinase for signaling.

Hexose Sensor Proteins In yeast, membrane proteins with homology to hexose transporters are present that function as glucose sensors $(116,117)$. These SNF3 and RGT2 proteins sense low and high levels of glucose, respectively. Dominant mutations in the SNF3 and RGT2 proteins have been identified that initiate signaling in the absence of glucose. Also in yeast, a membrane-bound glucose sensor GPR1 has recently been identified (89). GPR1 is a G protein-coupled receptor specifically required for glucose activation of the cAMP pathway.

Such hexose sensing proteins are also present in plants, although their molecular nature and cellular location are still obscure. Glucose analogs like 3-O-mGlc and 6-dGlc can initiate signaling but are not phosphorylated by hexokinase (Figure 1). In a cell suspension-culture of Chenopodium rubrum, the addition of either glucose or 6-dGlc induces the expression of genes for extracellular invertase and sucrose synthase $(46,133)$. In the unicellular green alga Chlorella kessleri, glucose and 6-dGlc induce several genes, including a glucose transporter gene (60). The sugarand amino acid-induced patatin class I pat (B33) promoter is also induced by the glucose analogs 6-dGlc and 3-O-mGlc in transgenic Arabidopsis plants harboring the Pat (B33)-iudA construct (101). These results suggest that plant cells sense the presence of hexoses as such, independently of hexose phosphorylation.

Hexokinase An extensive body of literature suggests that hexose phosphorylation by hexokinase (HXK) is an important sugar sensing mechanism in yeast and 
animal systems $(18,36,40,51,79,102)$. Somehow the active hexokinase initiates a signaling cascade that leads to altered gene expression. It was proposed that the yeast Hxk2 protein is itself located in the nucleus as part of a DNA-protein complex that binds to glucose-repressed genes (59).

In plants, a similar HXK-dependent sugar sensing mechanism controls many processes and metabolic pathways. Sugar-induced feedback inhibition of photosynthesis has been described for many species and this overrides regulation by light, tissue type, and developmental stage $(75,91,144)$. Increased carbohydrate levels lead to inhibition of photosynthesis and a decrease in ribulose-1,5bisphosphate carboxylase (Rubisco) protein, other Calvin-cycle enzymes, and chlorophyll. Moreover, this inhibition of photosynthesis is sustained by repression of many genes encoding proteins involved in photosynthesis (PS-related genes). For example, decreased Rubisco small subunit (RBCS) transcript levels were observed in a $C$. rubrum photoautotrophic cell suspension when cultured in the presence of glucose (91). Glucose phosphorylation is essential for repression since non-phosphorylatable analogs such as 6-dGlc and 3-O-mGlc have no effect. Jang \& Sheen (75) used a maize protoplast transient expression system to monitor the effects of various sugars on promoter activity of photosynthesis genes. They observed that HXK substrates such as glucose and 2-dGlc induce repression, whereas various metabolic intermediates were ineffective. The involvement of HXK was further suggested by the observation that the HXK-inhibitor mannoheptulose (MNH) blocks the 2-dGlc-mediated repression (75).

A transgenic approach was recently taken to provide more direct evidence for the involvement of HXK in repression of photosynthesis genes (73). Two HXK genes from Arabidopsis, AtHXK1 and AtHXK2, have been cloned and used in overexpression and antisense experiments to investigate the in vivo function of HXK in sugar sensing. Germination of wild-type Arabidopsis seeds on a medium containing $6 \%$ glucose inhibits hypocotyl elongation and greening of the seedlings, and represses expression of photosynthesis genes. Antisense plants with reduced expression of AtHXK1 and AtHXK2 are less sensitive to these effects of glucose than wild-type Arabidopsis, whereas enhanced glucose sensitivity was observed in HXK-overexpressing plants. In a separate experiment, the yeast $H X K 2$ gene was introduced in Arabidopsis and glucose sensitivity was tested. Such transgenic $H X K 2$-overexpressing lines showed reduced glucose sensitivity similar to the HXK antisense lines. The explanation given for this observation is that the yeast enzyme phosphorylates cellular glucose, thereby reducing enzymatic and signaling activity of the endogenous HXKs, which results in reduced glucose sensitivity. Moreover, yeast HXK apparently has no signaling effect in plants. Overexpression of the Arabidopsis $A t H X K 1$ in transgenic tomato plants leads to a phenotype that includes reduced photosynthetic activity; a regulatory role for HXK was also proposed (25).

HXK-mediated sugar sensing is present in non-green tissues as well. In a cucumber cell culture system, the glyoxylate cycle genes malate synthase $(M S)$ and isocitrate lyase $(I C L)$ were shown to be repressed by the addition of glucose to the growth medium. 2-dGlc and mannose could mimic this effect but 3-O-mGlc, which is not a HXK substrate, could not $(48,49)$. Moreover, mannose or 2-dGlc inhibit 
germination of Arabidopsis seedlings (121). Adding the HXK inhibitor MNH to the growth medium could relieve this inhibition. In this system 3-O-mGlc and 6-dGlc had no effect, which shows that hexose uptake per se is not involved. It was concluded that mannose inhibits Arabidopsis germination via a hexokinasemediated step. In celery, the activity of the mannitol-catabolizing enzyme mannitol dehydrogenase (MTD) is repressed by sugars that are substrate for HXK but not by 3-O-mGlc (124). This inhibition of MTD activity could be relieved by MNH. These studies are in agreement with the notion that HXK is of major importance for hexose sensing in the plant's life cycle.

The function of HXK as a hexose sensor in plants has not been generally accepted $(35,54,58)$. Herbers et al $(58)$ suggested that hexose sensing occurs in association with the secretory (Golgi-ER) system. Experiments in which a yeast invertase was expressed in the plant apoplast or vacuole result in monosaccharide release, which leads to repression of PS-related genes such as $C A B$, encoding chlorophyll-a/b binding protein. Since the cytosolic expression of yeast invertase did not induce these changes in gene expression, it was concluded that sensing occurs in association with the endomembrane system independent from HXK. Moreover, Halford et al (54) have questioned the sensing function of HXK. These authors argue that the reduced energy status of the cell due to HXK activity may feed into signaling systems, as was found for the AMP-activated protein kinase (AMPK), the animal homologue of the yeast SNF1 kinase.

Clearly, the molecular details on the sugar sensing function of HXKs and its signaling to downstream components must be resolved (107), e.g. by functionally separating the enzymatic and signaling function of HXK via mutation analysis. Dominant signaling mutations such as those present in mutant SNF3 and RGT2 hexose binding proteins have not yet been identified for plant HXKs, but for yeast there are reports on the separation of enzymatic and signaling functions $(61,90)$. Such a separation of functions is essential to understand the way in which HXK operates as a sensor. Also unclear is how the activated HXK interacts with downstream components of the signaling pathway. More plant-specific questions relate to the diversity of hexokinase genes, their regulation, tissue-specific expression patterns, intracellular localization, and the possible control systems that operate on HXKs, such as the trehalose system $(45,157)$. Mutants should help in elucidating the role of HXK in sugar sensing; recently, the first Arabidopsis hexokinase mutants were isolated (107).

Several other sugar kinases in addition to HXK are present in plants; fructokinase, galactokinase, and arabinose kinase. The Arabidopsis galactokinase (GAL1) and arabinose kinase (ARAl) genes have been cloned and an arabinose kinase deficient mutant ( aral) has also been identified $(81,145)$. Whether these enzymes have signaling function similar to the proposed HXK function is unclear. The recent identification of an Arabidopsis mutant with a disrupted fructokinase 2 gene should help in answering this question (120).

Galactokinase (Gallp) has been implicated in monosaccharide sensing in yeast. Gallp can bind to Gal80p, which is the inhibitor protein of the transcriptional regulator Gal4p. Gallp binds to Gal80p in the presence of galactose and ATP, 
allowing Gal4p to activate expression of the $G A L$ genes $(123,186)$. Galactokinase enzymatic activity was dispensable for the Gallp-Gal80p interaction, as shown by a kinase-negative Gallp mutant that retains its regulatory function.

Other products of intermediary metabolism are likely being sensed. For example, in the maize protoplast system it was found that in addition to glucose, acetate also inhibits expression of photosynthesis genes (75). However, it has been argued that intracellular acidification may cause the acetate-induced repression of photosynthesis genes (35).

Trehalose Trehalose biosynthetic enzymes have a regulatory function in yeast that somehow controls HXK activity and signaling. However, the molecular details of this regulatory mechanism are unclear (157). It has now become apparent that all flowering plants are capable of trehalose biosynthesis and degradation $(11,44,45,167)$. Genes encoding TPS- and TPP-like proteins have been cloned from several plant species and these are present as multigene families $(11,45,167)$. These plant TPS and TPP genes can functionally complement yeast $t p s$ and $t p p$ mutants, respectively. Overexpression of bacterial and yeast TPS and TPP genes in plants leads to opposite phenotypes $(45,62,134)$. These phenotypes, and the detailed analysis of the transgenic plants, suggest that plant trehalose metabolism also has a function in sugar sensing in plants. Interestingly, it was reported that trehalose addition to soybean induced sucrose synthase and alkaline invertase activity (110).

\section{THE SIGNAL TRANSDUCTION CASCADE}

The sugar sensors feed information into signal transduction cascades that lead to different plant responses. Our knowledge of this process is limited but progress is being made through different approaches. The involvement of protein kinases, protein phosphatases, and other signal transduction mediators such as $\mathrm{Ca}^{2+}$ and calmodulin have been proposed (Figure 3). Furthermore, the importance in plants of SNF1-like protein kinase complexes and interacting proteins in sugar sensing is now being established. In addition, other kinases and phosphatases have been identified that control activity of enzymes in intermediary metabolism such as sucrose phosphate synthase (SPS), sucrose synthase (SS), and nitrate reductase (NR). These protein kinases and phosphatases are most likely connected to sugar signaling pathways.

\section{Protein Kinases, Protein Phosphatases, $\mathrm{Ca}^{2+}$, and Calmodulin}

Protein Kinases, Protein Phosphatases, $\mathrm{Ca}^{2+}$, and Calmodulin Protein phosphorylation and dephosphorylation, $\mathrm{Ca}^{2+}$, and calmodulin have been implicated in sugar-mediated signaling of the sweet potato and Arabidopsis genes encoding $\beta$-amylase, sporamin, and the small subunit of AGPase $(106,113,154)$. Specific inhibitors of protein-Ser/Thr phosphatases 1 (PP1) and 2A (PP2A) such as okadaic acid, microcystin-LR, and calyculin A blocked the sugar induction of these genes 


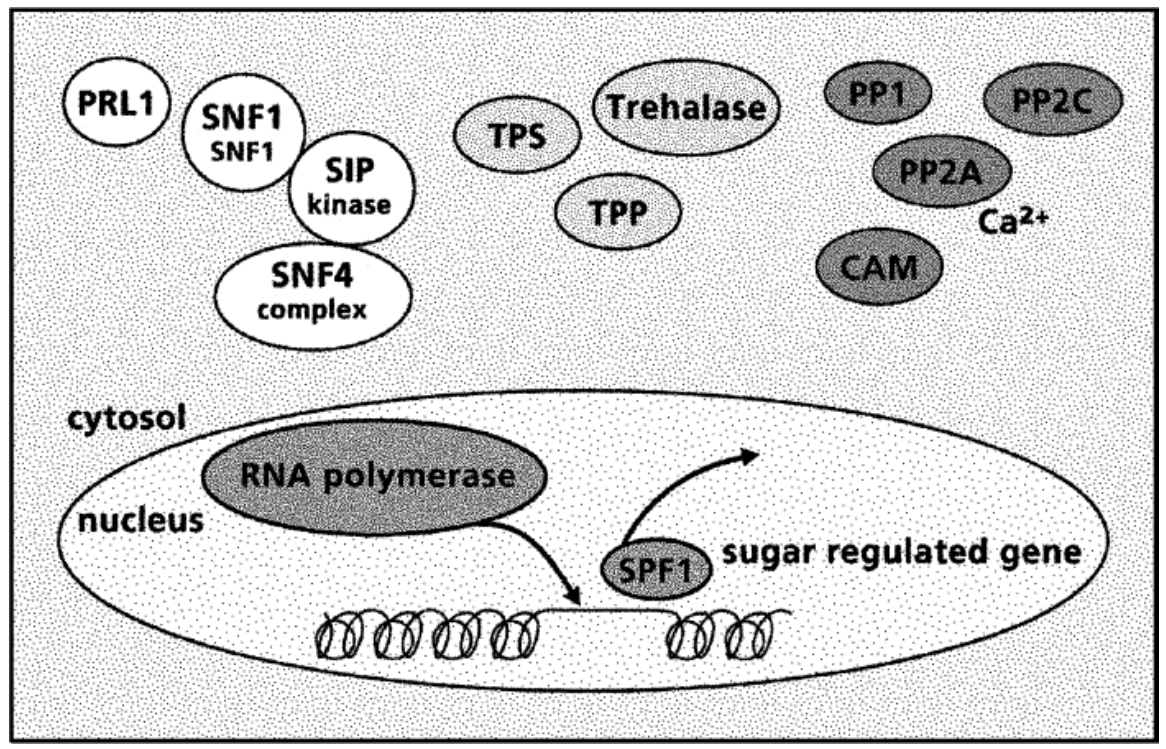

Figure 3 Possible intermediates in sugar-induced signaling in plants. The individual components are discussed in the text.

in sweet potato as well as reporter gene expression in $\beta$-amylase promoter-iudA (AMY-GUS) fusion genes in tobacco (154). In addition, inhibitors of Ser/Thr protein kinases, staurosporine and K-252a, inhibited the sugar induction of the $A M Y$-GUS gene in tobacco (115). These authors reported on a sugar-inducible calcium-dependent (calmodulin-domain) Ser/Thr protein kinase (CDPK) associated with the plasma membrane in leaf tissue of tobacco.

The involvement of $\mathrm{Ca}^{2+}$ and calmodulin in sugar-induced $\beta$-amylase and sporamin expression was suggested from experiments with calmodulin inhibitors $\mathrm{La}^{3+}$ and EGTA and the $\mathrm{Ca}^{2+}$-channel blockers diltiazem and nicardipine (113). Moreover, cytoplasmic $\mathrm{Ca}^{2+}$ concentrations increase upon incubation with sugars, as was demonstrated in experiments with transgenic tobacco plants that expressed a $\mathrm{Ca}^{2+}$-sensitive photoprotein of jellyfish, aequorin (113).

The $C$. rubrum cell culture system has been used to study the sugar-regulated expression of the RBCS, RBCS, CINI (encoding cell wall invertase), and PAL (encoding phenylalanine ammonium lyase). In this system, the source-specific $R B C S$ gene is repressed by sugars, whereas the sink-specific CIN1 gene and the pathogen-induced PAL gene are sugar induced (35). These three genes were found to be coordinately regulated by glucose in an HXK-independent way. Four different protein phosphatase inhibitors were able to mimic the glucose-mediated regulation of these three genes. Thus protein dephosphorylation is involved in transducing the sugar signal. Moreover, it appears that sugar signaling requires both de novo protein synthesis and the activation of MAP kinases. The glucose-regulated expression of these three genes is mimicked by stress-related stimuli such as addition of the fungal 
elicitor chitosan. Interestingly, the glucose- and elicitor-induced regulation of these three genes involves different perception and signal transduction systems since the protein kinase inhibitor staurosporine inhibits elicitor-induced but not glucoseinduced gene expression response. Thus protein kinase activity is essential for transmission of the elicitor signal, whereas protein phosphatase activity is essential for transmission of the glucose signal. These results do not support the model that elevated glucose concentrations as such are the primary signal for induction of stress-related genes $(58,75)$.

\section{The SNF1 Kinase Complex}

The glucose-repressed state in yeast is relieved by the action of the SNF1 kinase complex, a protein-serine/threonine kinase. A shift to low glucose concentrations somehow activates the SNF1 kinase and this results in the phosphorylation of the DNA binding protein MIG1. When glucose is available, MIG1 interacts with the repressor complex SSN6/TUP1 to maintain the glucose-repressed state (163). At low glucose concentrations, MIG1 is phosphorylated and translocated to the cytosol $(18,29,164)$. The dissociation of the repressive complex enables the activation of glucose-repressed genes through the involvement of the SNF/SWI chromatin remodeling machine. These glucose-repressed genes encode functions that allow growth of the cells on alternative fermentable carbon sources such as sucrose and galactose. The SNF1 kinase complex is a heterotrimeric protein that consists of the SNF1, SNF4, and a member of the SNF-interacting (SIP) protein family (SIP1-4, GAL83). The SNF1 protein harbors the catalytic function, whereas SNF4 is the activating subunit (77). The SIP proteins function as adapters between the SNF1 and SNF4 subunits. In yeast the function of the different subunits in the SNF1 complex in relation to glucose sensing has been thoroughly investigated and a detailed model presented (18).

The SNF1 kinase complex is evolutionarily conserved and has been found in animals and plants (Table 2). The animal complex is the AMP-activated protein kinase (AMPK) $(55,56,83)$. AMPK is also a heterotrimeric complex and the subunits share considerable homology at the amino acid level with the yeast SNF1 kinase complex subunits. SNF1 kinase homologues have been cloned from many plant species [for a compilation see (53)]. The classification of known plant

TABLE 2 Subunit composition and nomenclature of yeast, mammalian, and plant SNF1 kinase complexes

\begin{tabular}{lllll}
\hline Yeast & Mammals & Plant & MW plant enzyme & Function $^{\mathrm{a}}$ \\
\hline SNF1 & $\alpha$ & SnRK $^{\mathrm{b}}$ & $\sim 58 \mathrm{kD}$ & Catalytic \\
SNF4 & $\gamma$ & SNF4 homologue & $\sim 40 \mathrm{kD}$ & Activator \\
SIPs & $\beta$ & SIP homologue & $\sim 30 \mathrm{kD}$ & SNF1 + 4 bridging \\
\hline
\end{tabular}

${ }^{\mathrm{a} A p p r o x i m a t e ~ m o l e c u l a r ~ w e i g h t s ~(M W) ~ a r e ~ p r o v i d e d ~ f o r ~ t h e ~ p l a n t ~ s u b u n i t s . ~}$

${ }^{\mathrm{b}} \mathrm{SnRK}, \mathrm{SNF} 1$-related kinase. 
SNF1-related sequences and their expression patterns has been reviewed recently (53). The other components of the plant SNF1 kinase complex have also been identified. For example, the potato SNF1 kinase was used in a yeast two-hybrid system and interacting proteins were found homologous to the yeast GAL83 protein (93). Arabidopsis SNF4 and SIP genes have also been cloned (14). Several of these plant SNF1, SNF4, and SIP genes complement the corresponding yeast mutations, showing the high degree of functional conservation of the complex. In both plants and animals the constituents of the kinase complex are encoded by multigene families $(14,53,56,93)$.

The function of the AMPK complex in animals was proposed to be that of a fuel gauge $(55,56,83)$. Activation of the complex leads to energy preservation by inactivating ATP-consuming anabolic enzymes via phosphorylation. Target proteins of the AMPK complex include acetyl-CoA carboxylase (fatty acid synthesis) and 3-hydroxy-3-methylglutaryl-coenzyme A (HMG-CoA) reductase (isoprenoid and sterol synthesis). Phosphorylation of these enzymes leads to their inactivation. AMPK activity can be assayed in vitro by determining the phosphorylation of the SAMS peptide. This peptide is derived from the phosphorylation site of the rat acetyl-CoA carboxylase (His Met Arg Ser Ala Met Ser Gly Leu His Leu Val Lys Arg Arg). Plant SNF1-related protein kinases also phosphorylate this peptide $(4,100)$.

Molecular and physiological analysis of the SNF kinase complex in plants is still limited. However, antisense suppression of a potato $S N F 1$ homologous gene was found to result in loss of sucrose-inducibility of sucrose synthase (125). Moreover, the SAMS peptide kinase activity was reduced in these plants. Two different kinase complexes have been biochemically identified in spinach (153). One such complex may be involved in diverse phosphorylation functions. Moreover, the exchangeable SIP/GAL83 proteins may direct the kinase to different cellular substrates. This would explain the variety of processes in yeast in which the SNF1 kinase complex is active: thermotolerance, sporulation, cell cycle progression, and peroxisome biogenesis (18).

In addition to this proposed function in coupling sugar perception to altered gene expression, the SNF kinase complex likely controls the activity of several enzymes in plant metabolism and in this way allows for rapid changes in metabolism. The activity of plant nitrate reductase (NR) is controlled by phosphorylation at a specific serine residue (in spinach, serine-543). Phosphorylation per se does not alter NR activity but it allows for the binding of 14-3-3 proteins (Figure 4). Once complexed with a 14-3-3 protein, the phosphoserine-NR is inactivated (3). It appears that many enzymes in intermediary metabolism are controlled through protein phosphorylation and 14-3-3 protein binding. These proteins include NR, SPS, $\mathrm{SS}$, and HMG CoA reductase $(4,34,67,153,161)$. The phosphorylation of these proteins by SNF1-like and other protein kinases, followed by binding of 14-3-3 proteins, results in rapid adaptation of enzymatic activities and metabolic pathways to changing conditions. A family consisting of at least ten 14-3-3 genes has been cloned from Arabidopsis (181), and the encoded proteins are clearly involved in controlling diverse cellular processes in plants. A number of 14-3-3-binding 
Figure 4 Control of enzymatic activity by protein kinase activity and 14-3-3 protein binding to the phosphorylated enzyme. As an example nitrate reductase (NR) is shown but this model has been proposed for several enzymes in plant carbohydrate metabolism.

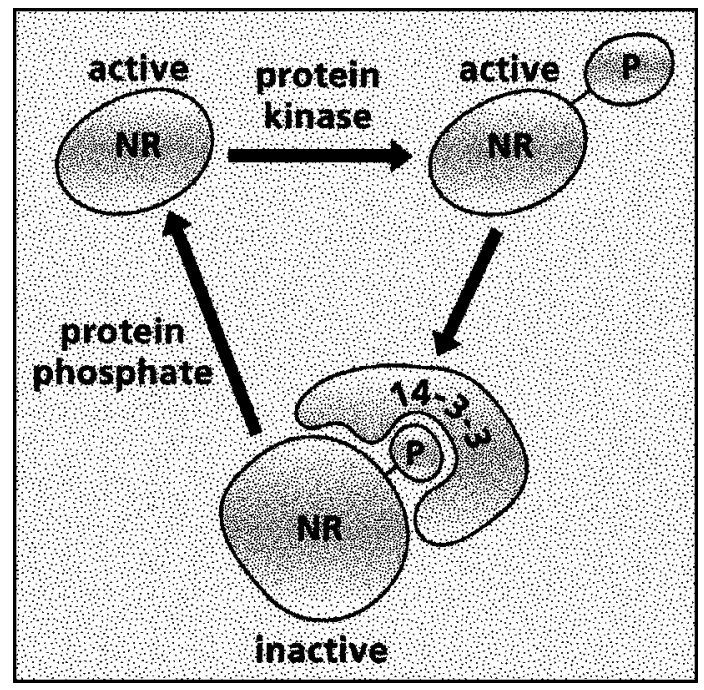

proteins have been isolated from cauliflower by using affinity chromatography on immobilized 14-3-3 proteins and specific elution with a 14-3-3-binding phosphopeptide (108). These proteins were identified as being active in diverse cellular processes. One of these proteins is a calcium-dependent (calmodulin domain) protein kinase (CDPK) that phosphorylates NR and thereby makes it a target for inhibition by 14-3-3 proteins. Thus it appears that this CDPK is itself a target for phosphorylation and 14-3-3 protein binding.

Interestingly, the nitrate reductase phosphoprotein-14-3-3 protein complex is AMP sensitive. Addition of 5'-AMP or homologous compounds leads to the dissociation of the complex, apparently through the binding of the $5^{\prime}$-AMP to a domain on the 14-3-3 protein $(2,80)$. Although the physiological relevance of this observation is unclear, enzyme activities may be directly linked in this way to energy charge of the cell.

Other protein kinases in addition to the SNF kinase complex have been identified that also phosphorylate enzymes in intermediary metabolism. A single enzyme can be a target for different protein kinases that regulate its activity in opposite ways. For example, SPS can be both activated and repressed by site-specific protein phosphorylation (161). Diurnal regulation of SPS is controlled by serine-158 phosphorylation through the activity of a SNF1-like kinase that leads to inactivation. This control is overridden by stress-induced activation via a CDPK-mediated serine-424 phosphorylation (161). Moreover, enzymes such as NR, SPS, HMG CoA reductase, and SS can also be phosphorylated by $\operatorname{CDPK}(33,34,67,162)$. Phosphorylation of SS selectively activates the sucrose cleavage reaction, thereby releasing UDP-glucose and fructose for intermediary metabolism (67). A spinach NR serine-543 phosphorylating enzyme has recently been purified and its identity 
established by partial amino acid sequencing of the protein (33). The peptide sequences of the spinach protein were very similar to the Arabidopsis $C D P K 6 / C P K 3$ gene $(63,64)$.

These kinases and phosphatases are themselves targets for regulation. What emerges is a highly complex interactive web that is functional in fine-tuning the assimilatory and respiratory processes, and adapting to continuously changing conditions. Biochemical and molecular knowledge about these kinases is rapidly increasing but the links with sugar signaling cascades need strengthening. The identification and analysis of mutants such as prll (see below) should fill this gap.

The biochemical and molecular details of the dephosphorylating enzymes remain to be established. Mammalian protein phosphatases PP2A and PP2C can inactivate plant SNF1 kinase activity (34). Interestingly, the plant PP2C-type protein phosphatase activity encoded by the ABII locus can also inactivate SNF1 kinase. This led MacKintosh (100) to suggest a function of other plant PP2Cs, like the serine/threonine receptor-associated kinase-associated protein phosphatases (KAPP) $(16,179)$ in regulating plant SNF1-like kinases. SNF1-like protein kinases probably are involved in other metabolite signaling pathways as well. A SNF1-like kinase was implicated in Chlamydomonas in the responses to sulfur limitation (26).

\section{PRL1, A SNF1 Kinase Complex Interacting Protein}

A T-DNA tagged Arabidopsis mutant that shows growth defects on media containing $175 \mathrm{mM}$ sucrose or glucose was discovered by Koncz and colleagues $(111,138)$. The T-DNA tag allowed identification of this PLEIOTROPIC REGULATORY LOCUS 1 (PRL1). PRL1 encodes a WD protein that is localized in the nucleus. The prll mutant shows a rather pleiotropic phenotype that includes developmental alterations such as a short root. Moreover, $\mathrm{prll}$ is hypersensitive to ethylene, auxin, cytokinin, ABA, and cold. The presence of 0.1 micromolar ABA already results in prll bleaching and growth reduction, whereas this concentration has no effect on wild type. Many genes that are up-regulated by sugar or cytokinin are overexpressed in the mutant, leading to overproduction of anthocyanin and starch.

Remarkably, in a yeast two-hybrid screen for interacting partners, the PRL1 protein was found to interact with AKIN10 and AKIN11, the Arabidopsis homologues of yeast SNF1 protein kinase $(9,42)$. In yeast this PRL1-AKIN interaction was dependent on the presence of glucose in the medium. Low glucose increased the strength of the interaction, which suggests that these plant proteins are responsive to yeast endogenous glucose-derived signals. PRL1 probably inhibits the phosphorylating activity of AKIN10 and 11, as shown in in vitro experiments with a peptide substrate. In yeast the SNF1 kinase is activated by glucose starvation but, in contrast, sugar feeding to light-grown plants stimulated peptide-substrate kinase activity. This sugar-induced kinase activity is independent of the presence of PRL1 since it is observed both in wild-type and in the prll mutant. These observations make it difficult to construct a model on PRL1 function. In addition 
to the AKIN10 and 11 proteins, PRL1 was found to interact with other proteins in yeast two-hybrid screens. This and the pleiotropic nature of the mutation suggest that PRL1 is a central regulator in several processes (9).

\section{Nuclear Processes}

Sugar signaling can result in altered transcriptional activity of target genes, and for most genes documented this seems to be the mode of control. Transcriptional regulation is not the only response to sugars, and cytosolic targets for control have been identified. Enzyme activity can be directly regulated, as proposed for the SNF1 kinase complex. Moreover, the above-mentioned sucrose-regulated ATB2 gene is controlled at translation (135). In addition, modulating mRNA stability is a major control element for cereal $\alpha$-amylase gene expression (20).

Several sugar-inducible promoters have been analyzed in some detail to locate sugar-responsive cis-elements. In mutagenesis experiments, promoter elements were located that confer sucrose-inducible expression when fused to a heterologous core promoter sequence. Such sucrose-responsive elements (SURE) in the patatin class I promoter interact in gelshift assays with Sucrose Response Factors $(50,97)$. Moreover, SURE elements may show similarity to the SP8 motifs in the promoter region of the sucrose-induced $\beta$-amylase and sporamin genes from sweet potato (71). These SP8 motifs are recognized by the SP8BF nuclear factor $(70,71)$. A nuclear factor with similar binding specificity to SP8BF also binds to the SURE elements in the patatin promoter. The promoter of the sugar-inducible potato SUS4 gene encoding sucrose synthase contains SURE elements (39). Moreover, SURE homologous sequences were also observed in other sucrose-inducible sucrose synthase genes such as Arabidopsis (ASUS1), maize (SUS1), and rice (SUS1) [for references, see (39)]. Direct experimental evidence for a function of SURE homologous sequences in these promoters is lacking. Moreover, the SP8/SURE elements are not present in the $5^{\prime}$-upstream regions of all sugar-inducible genes. Nuclear factors that are potato tuber-specific or induced by sucrose in leaves were identified that bind to the class-I patatin promoter (85). The binding of these factors was localized to four different regions of this promoter including a SURE-like region.

Plant genes encoding isocitrate lyase and malate synthase genes are developmentally regulated and are induced by starvation and germination. These genes are also responsive to sugars, and the promoter elements involved in repression have been localized. Distinct cis-acting elements have been identified for developmental control and sugar repression in these genes $(27,48,49,126,140)$. The sugar repression elements seem not to resemble the SURE elements.

A cDNA clone encoding a new type of DNA-binding protein, SPF1, that binds the SP8 motif was isolated from a sweet potato petiole cDNA library (71). Interestingly, SPF1 transcript levels decreased when leaf-petiole cuttings were treated with sucrose concentrations that induce accumulation of sporamin and $\beta$-amylase mRNAs. This observation suggests that SPF1 is a negative regulator. A putative SPF1 homologue has recently also been isolated from cucumber (84). 


\section{CEREAL SEED GERMINATION}

The cereal seed germination system provides an interesting system for the analysis of sugar-regulated gene expression. During seed germination starch is mobilized by the action of $\alpha$-amylases. Cereal $\alpha$-amylases are encoded by multigene families. In rice nine members comprise the $\alpha$-amylase gene family (159). During cereal seed germination $\alpha$-amylases are produced by the scutellar layer of the embryo and by the aleurone layer of the endosperm. The different members of the gene family are expressed in a tissue-specific and developmentally specific way. $R A m y 3 D$ [nomenclature according to (159)] is the major gene expressed in the rice scutellum during germination. At the rice seedling elongation stage $R A m y 1 A$, $R A m y 3 B, R A m y 3 C$, and $R A m y 3 E$ are expressed (159).

Glucose generated by the $\alpha$-amylases is transported to the embryo for growth of the seedling. Interestingly, when glucose levels exceed demand $\alpha$-amylase gene expression is down-regulated in a process that involves sugar sensing. This regulatory feedback system has been studied in detail in intact tissues and in suspension cultured cells $(69,82,185)$. For the RAmy $3 D$ gene it was found that HXK is most likely involved in transmitting the glucose signal. The hexokinase substrate 2-dGlc can induce signaling and this signaling is inhibited by the HXK inhibitor glucosamine. Moreover, 3-O-mGlc and 6-dGlc are not effective in signaling (165). Also, it was found that $\alpha$-amylase expression is inhibited in the barley seed germination system by hexoses that are substrates for HXK but not by other hexoses (122).

Pharmacological studies have also been performed with sugar-repressed genes. In cultivated rice cells, the expression of $\alpha$-amylase genes like $R A m y 3 D$ is repressed by sugars (99). In this system, protein phosphatase inhibitors strongly induce amy $3 D$ expression and an AMP-activated protein kinase may be involved in induction.

Several, but not all, of the $\alpha$-amylase genes are GA responsive. GA induces these $\alpha$-amylase genes but sugars override the GA signal and repress gene expression. The sugar- and GA-responsive elements in the promoter of the RAmylA gene appear to overlap, which indicates that the two signal transduction pathways communicate at a point upstream of the promoter elements (109). The promoters of the $\alpha$-amylase genes contain important cis elements for developmentally specific expression and for sugar regulation, as was found in promoter-reporter constructs and nuclear run-on experiments (146). In addition, regulation of mRNA stability appears to be important as well since the $R A m y 3 E$ mRNA half-life was reduced from $12 \mathrm{~h}$ in sugar-starved cells to less than $1 \mathrm{~h}$ when sugar was added to the rice suspension cultured cells (146). The major mRNA stability determinants were mapped to specific regions in the $3^{\prime}$-UTR region of the mRNA. These regions did not affect transcription of the gene $(19,20)$.

GA induces $\alpha$-amylase activity in the scutellum and aleurone of germinating barley seeds. This GA-mediated $\alpha$-amylase induction is repressed by sugars in the scutellum only (122). As noted above, sugars that are substrate for HXK are effective in this repression and sugar repression overrides the GA-inductive effect. 
Sugars also repress $\alpha$-amylase expression in the barley GA-constitutive response slender mutant, and it was concluded that sugars negatively interfere with GA signal transduction (122). The sugar repression of GA-induced $\alpha$-amylase activity and of constitutive $\alpha$-amylase activity in the slender mutant is mimicked by ABA application, which prompted the suggestion that ABA mediates the glucose effect (see Interacting Signaling Pathways, below). However, glucose decreased ABA concentrations in barley embryos, and ABA sensitivity in this system also seemed to be unaltered, as indicated by expression of the ABA-sensitive Rab16A gene (122).

\section{SEED DEVELOPMENT}

Sugar import and utilization during leguminous seed development have been particularly well studied. Hexoses and sucrose serve specialized functions in different phases of seed development. This conclusion was based on analysis of the spatial and temporal expression of genes encoding sucrose metabolizing enzymes and hexose and sucrose transporters $(156,172-174,176,180)$. Hexose metabolism is associated with meristematic activity (cell division) in the developing embryo, whereas sucrose metabolism is associated with starch and protein storage functions. Meristematic versus storage functions could be manipulated by incubating embryos in media with different hexose-to-sucrose ratios and by seed-specific expression of the yeast invertase gene in Vicia narbonensis (175). This model was further supported by high-resolution histographical mapping of glucose concentrations in developing cotyledons of Vicia faba. Glucose co-mapped with regions of meristematic activity, and it was suggested that glucose functions as a developmental trigger molecule or morphogen (13). The importance of monosaccharides for seed development was also shown in maize, where the small seed miniature 1 mutant has a defect in the gene encoding extracellular invertase (22). Moreover, carbohydrate metabolism is disturbed in the Arabidopsis wrinkledl mutant during seed development. This mutant shows reduced HXK activity (38).

Sugars as signals for developmental switches in seed development must act in concert with other factors and phytohormones. In Arabidopsis such factors may include the more general regulators of seed development ABI3, LEC1, and FUS3 $(28,129,180)$. The action of these proteins may not be restricted to seed development as originally proposed. For example, the expression pattern of the Arabidopsis $A B I 3$ gene suggests a function in vegetative quiescence processes (131).

\section{INTERACTING SIGNALING PATHWAYS}

Sugar-signaling pathways do not operate in isolation but are part of cellular regulatory networks. Recent results clearly show cross talk between different signaling systems, especially those of sugars, phytohormones, and light. 


\section{Ethylene}

A close interaction between HXK- and ethylene-mediated signaling pathways was revealed by the analysis of the Arabidopsis ginl mutant (188). This mutant is resistant to elevated (6\%) glucose amount. Moreover, elevated sugar levels do not repress PS-related genes as they do in wild-type plants. The ginl mutation is epistatic to HXK in the glucose signaling pathways since combining gin 1-1 with $A t H X K 1$ overexpressing lines produced plants that showed the same glucose insensitivity phenotype and had the same appearance as gin 1-1. The gin 1 mutants germinate faster, are smaller, and have darker green rosettes than wild-type, and this phenotype is reminiscent of wild-type plants treated with ethylene. Interestingly, the gin 1-1 phenotype could be copied in wild-type plants by treatment with the ethylene precursor ACC. In addition, the ethylene-overproducing mutant eto 1-1 and the ethylene constitutive response mutant $\operatorname{ctr} 1-1$ are also glucose insensitive. Conversely, the ethylene-insensitive mutant etr $1-1$ shows a glucose hypersensitive phenotype. In the etr $1-1$ mutant an ethylene receptor is mutated, which results in a dominant ethylene-unresponsive phenotype (66). Further investigations showed that GIN1 acts downstream of ETRI in the ethylene-signaling pathway. These findings reveal a close interaction between the glucose- and ethylene-signaling pathways. Glucose signaling through HXK and GIN1 down-regulates a branch of the ethylene-signaling pathways that stimulates germination and cotyledon and leaf development (188).

\section{Abscisic Acid and Gibberellic Acid}

The cloning and analysis of the sun 6 mutation $(30,68)$ led to the discovery that an intact ABA signal transduction chain is important for hexokinase-dependent glucose signaling (68). As well as being sucrose-insensitive, the sun6 mutant is also insensitive to glucose and mannose. Moreover, elevated sugar levels in sun6 do not repress photosynthesis genes. In accordance with these results, whole plant photosynthesis in mature sun6 rosettes was found to be more resistant to the glucose analog 2-dGlc than in wild-type plants (166). The identification of a sun6 allele in a transposon-tagged seed collection allowed cloning of the gene. SUN6 is identical to the previously cloned ABI4 gene (37). The SUN6/ABI4 protein falls in the group of AP2-domain transcription factor genes and the sun6 mutant bears a stop codon in the AP2 domain. The sun6 mutation is allelic to abi4 and, like $a b i 4$, germinates on ABA-containing medium. Remarkably, all Arabidopsis aba and $a b i$ mutants are, to varying degrees, sugar sensing mutants (68). These results suggest that hexokinase-mediated sugar signaling requires an intact ABA signal transduction chain. It is unclear whether sugars enhance cellular ABA sensitivity or increase ABA levels. The ABI4/SUN6 protein is important during germination and photosynthetic growth. Down-regulation of photosynthesis genes is mediated through ABI4/SUN6, which allows sugar supply to be matched with demand. At germination, ABI4/SUN6 is involved in controlling the mobilization of seed 
reserves in an ABA- and sugar-dependent way. That ABA inhibits germination by restricting reserve mobilization was also shown by Garciarrubbio et al (41). These findings may explain the sensitivity of Arabidopsis seeds to mannose (121). Mannose activates HXK signaling, which activates the ABI4/SUN6 gene or gene product through the ABA pathway, thereby restricting reserve mobilization.

The close relation between HXK-mediated sugar sensing and ABA signal transduction may explain many earlier observations on the similar effects of ABA and sugar application on gene expression. For example, in addition to sugars, ABA also inhibits expression of light- (phytochrome) dependent PS-related genes $(6,21,92,103)$. This relationship with light and sugars is also apparent for other phytochrome-regulated genes. Interestingly, phytochrome signaling seems able to control plant ABA amounts, and one can speculate that phytochrome and sugars regulate photosynthesis-related and other genes in an integrated way by modulating ABA levels $(170 ; 171)$.

Many plants respond to elevated $\mathrm{CO}_{2}$ by repression of photosynthesis, possibly due to increasing sugar concentrations. Remarkably, this is not a cell-autonomous response but is controlled at the whole plant level (148). Phytohormones, like ABA, may mediate such systemic responses. Studies on the mechanism by which viral movement proteins affect assimilate allocation led to similar conclusions on systemic regulatory systems (98).

Sugars and ABA activate "sink-related" genes such as the sporamin and $\beta$-amylase genes of sweet potato (114). Moreover, sugars and ABA promote tuber development (182). In both cases, gibberellic acid (GA) has the opposite effect. Interestingly, modulation of phytochrome B levels in potato greatly affects tuber induction and development $(72,158)$, and one can speculate whether ABA is a mediator of this response.

ABA inhibits phloem loading of sucrose, whereas GA promotes export of assimilates $(1,168)$. Thus the ABA/GA balance may regulate cellular sugar levels. The opposite biological effect observed for ABA and GA may be due to interacting signal transduction pathways, as suggested by recent findings on SPINDLY (SPY) function. SPY is a negative regulator of GA action that shows homology to an O-linked $\mathrm{N}$-acetylglucosamine transferase (128). In a barley aleurone transient assay system, SPY repressed the GA-induced activity of $\alpha$-amylase. Surprisingly, SPY also increased promoter activity of the ABA-inducible dehydrin promoter in the absence of ABA. Thus GA- and ABA-responsive signal transduction chains may interact at a point upstream of SPY. For $\alpha$-amylase the ABA/GA response has been shown to act through a single cis element $(52,130)$. In Arabidopsis ABA sensitivity depends on the activity of a farnesyltransferase, the product of the ERAl gene (24). Interestingly, sucrose and glucose inhibit the expression of a protein farnesyltransferase in pea and thus might increase ABA sensitivity (187).

Sugars and ABA can also act in opposite ways, as was observed in a transgenic tobacco line harboring the Phaseolus phaseolin promoter-GUS gene. Applied ABA could induce this transgene and the endogenous $12 \mathrm{~S}$ globulin gene in prematuration zygotic embryos. Sucrose repressed this induction but addition of $\mathrm{Ca}^{2+}$ to the medium overcame the repression (17). 


\section{Cytokinins and Plant Development}

Cyclins are central regulators of the cell cycle and are targets for hormonal and metabolic control. In Arabidopsis cytokinin can activate the cell cycle through the D-type cyclin CycD3, which operates at the G1-S phase transition. Constitutive expression of $\mathrm{CycD} 3$ in transgenic plants alleviated the cytokinin requirement for cell division (127). Addition of sucrose to quiescent, sugar-starved Arabidopsis cells triggers expression of $\mathrm{CycD} 3$ and G1-S phase transition. The CycD2 gene is also induced by sugars (151). Whether sugar has a signaling function in this system or whether its metabolism induces the phase transition has not yet been closely investigated, but it is safe to predict such a signaling function of sugars in the control of the cell cycle.

Plants grown at elevated $\mathrm{CO}_{2}$ show an increase in apical meristem cell number and size, and a more rapid progression through the cell cycle has been observed in different plant species $(78,86)$. Growth at elevated $\mathrm{CO}_{2}$ leads to increased sugar levels that will activate sugar-sensing systems. In the apical meristems this may stimulate increased cell division rates through control of cyclin gene expression.

Many developmental processes are likely tightly linked to sugar signaling mechanisms, e.g. floral induction is dependent on a multifactorial signal that is transported to the vegetative apical meristem. Sucrose is an important component of this inductive signal $(8,96)$. Interesting in this respect is that the flowering-promoting gene $L E A F Y$ is induced by sucrose (10). Results obtained by Tang et al (155) also suggested the importance of sucrose and hexose as signal molecules in plant development. Interference with sucrose metabolism through antisense repression of invertase activity leads to developmental aberrations. These could be relieved by the addition of glucose and fructose to the medium. This effect of hexoses is reminiscent of the situation in developing bean seeds (180).

Many sugar-induced genes are also responsive to jasmonate, e.g. both jasmonate and sugars induce the expression of soybean vegetative storage protein (VSP) genes (7). Wounding, light, and phosphate also control expression of these VSP genes.

Carbon and nitrogen metabolism are tightly linked and it seems obvious that nitrogen-signaling pathways interact with sugar-signaling pathways $(95,118,141$, 152). Similar links can be expected for other metabolites as well $(26,112,137)$. Such interactions in turn may be controlled or mediated by phytohormones.

\section{Light}

Metabolizable sugars alter the responsiveness of plants to light; this has been described for the far-red light, PHYA-specific, signaling pathway. Sugars can block the so-called far-red light-induced block of greening that is caused by the PHYAspecific repression of protochlorophyllide oxidoreductase (5). Sugars negatively interfere with PHYA signaling, thereby protecting the plant against far-red-induced damage. Interestingly, in the sun6 mutant, sugars are not sensed and PHYA signaling is no longer inhibited by sugars (30). Arabidopsis lines that overexpress PHYB show reduced far-red light-induced PHYA signaling only if metabolizable sugars 
are present in the growth medium (147). These and other findings $(65,178)$ suggest a close interaction between sugar- and light-signaling pathways. For example, the sugar-induced expression of the Arabidopsis $\beta$-amylase is greatly enhanced by light, most likely through phytochrome signaling $(106,143)$.

Phytochrome affects activities of many enzymes in intermediary carbohydrate metabolism and anthocyanin biosynthesis. Overexpression of phytochrome in potato and tobacco leads to anthocyanin biosynthesis, activation of the Calvin cycle assimilatory genes, and the sucrose phosphate synthase gene $(142,183)$.

\section{Stress}

Elevated sugar concentrations can induce resistance to pathogen attack by inducing stress-related genes such as the PR proteins (132). Expression of yeast invertase in the plant apoplast or direct sugar feeding to leaves lead to increased levels of monosaccharides and PR proteins (58). Similarly, it was found that elevated sugar levels during fruit ripening in grape induce antifungal protein accumulation (139). It has been argued that monosaccharides directly induce stress-related genes, resulting in a systemic protective response (58). However, an alternative model suggests that a separate signaling pathway induces these stress-related genes (35). The sugar-responsive sporamin and $\beta$-amylase genes are also induced by elicitor and this induction is GA repressible (114). Since ABA induction of these genes is also GA repressible, sugars and elicitor could well have the ABA pathway in common.

In micorrhizal plant-fungus symbiosis, fungal hyphae penetrate the cortical cells of the host plant root to form arbuscules. This specialized structure allows for carbon transfer from the plant to the fungus, and gibberellic acid may be involved in this mobilization process (12). In the arbusculated cells assimilate unloading is probably maintained by the localized expression of sucrose synthase and soluble invertase. It is tempting to speculate on a signaling function for sugars in this specialized developmental process.

Many environmental stresses, most notably drought and cold, lead to major alteration in carbohydrate metabolism $(57,160,169)$, and most likely sugar signaling pathways interact with stress pathways to modulate metabolism. In a screen of selected sugar sensing mutants, one mutant was found to be impaired in the cold acclimation response (L Wanner \& S Smeekens, unpublished).

\section{CONCLUSION}

Significant progress has been made in sugar sensing research in recent years. Many Arabidopsis mutants have been identified with various sugar sensing or signaling phenotypes. Efficient cloning techniques will allow for the identification of the genes involved. Sugar-sensing pathways are clearly closely linked to other signaling pathways, most notably those of hormones. As these links are strengthened and worked out in molecular detail, analysis of mutants and the corresponding 
genes should provide new insights and identify connections to other pathways. More sophisticated mutant identification strategies are needed to address specific aspects of plant sugar sensing and signaling. For example, important and wellcharacterized mutants can be used as starting material to identify suppressor and enhancer mutations that are pathway specific.

Furthermore, the role of sugar transporters in sugar uptake and distribution over cellular compartments and its relation with sugar sensing and signaling must be better understood (94). The compartments in the cell where sugars are sensed must be identified. Clearly, sugar-signaling pathways are intimately woven into cellular signaling webs and what has been discovered so far gives only a glimpse of the complexity of the system overall.

\section{ACKNOWLEDGMENTS}

I am most grateful to Henriette Schlüpmann and Anne Kortstee for comments on the manuscript. I would also like to thank the other members of the Molecular Plant Physiology laboratory for valuable discussion.

\section{Visit the Annual Reviews home page at www.AnnualReviews.org}

\section{LITERATURE CITED}

1. Aloni B, Daie J, Wyse RE. 1986. Enhancement of $\left[{ }^{14} \mathrm{C}\right]$ sucrose export from source leaves of Vicia faba by gibberellic acid. Plant Physiol. 82:962-67

2. Athwal GS, Huber JL, Huber SC. 1998. Phosphorylated nitrate reductase and 14-3-3 proteins. Site of interaction, effects of ions, and evidence for an AMP-binding site on 14-3-3 proteins. Plant Physiol. 118:104148

3. Bachmann M, Huber JL, Liao PC, Gage DA, Huber SC. 1996. The inhibitor protein of phosphorylated nitrate reductase from spinach (Spinacia oleracea) leaves is a 143-3 protein. FEBS Lett. 387:127-31

4. Barker JHA, Slocombe SP, Ball KL, Hardie DG, Shewry PR, Halford NG. 1996. Evidence that barley 3-hydroxy-3-methylglutaryl-coenzyme A reductase kinase is a member of the sucrose nonfermenting-1related protein kinase family. Plant Physiol. 112:1141-49

5. Barnes SA, Nishizawa NK, Quaggio RB, Whitelam GC, Chua NH. 1996. Far-red light blocks greening of Arabidopsis seedlings via a phytochrome A-mediated change in plastid development. Plant Cell 8:60115

6. Bartholomew DM, Bartley GE, Scolnik PA. 1991. Abscisic acid control of $r b c S$ and $c a b$ transcription in tomato leaves. Plant Physiol. 96:291-96

7. Berger S, Bell E, Sadka A, Mullet JE. 1995. Arabidopsis thaliana Atvsp is homologous to soybean $V s p A$ and $V s p B$, genes encoding vegetative storage protein acid phosphatases, and is regulated similarly by methyl jasmonate, wounding, sugars, light and phosphate. Plant Mol. Biol. 27:93342

8. Bernier G, Havelange A, Houssa C, Petitjean A, Lejeune P. 1993. Physiological signals that induce flowering. Plant Cell 5:1147-55

9. Bhalerao RP, Salchert K, Bako L, Okresz L, Szabados L, et al. 1999. Regulatory interaction of PRL1 WD protein with Arabidopsis SNF1-like protein kinases. Proc. Natl. Acad. Sci. USA 96:5322-27 
10. Blazquez MA, Green R, Nilsson O, Sussman MR, Weigel D. 1998. Gibberellins promote flowering of Arabidopsis by activating the $L E A F Y$ promoter. Plant Cell 10:791-800

11. Blazquez MA, Santos E, Flores CL, Martinez-Zapater JM, Salinas J, Gancedo C. 1998. Isolation and molecular characterization of the Arabidopsis TPS1 gene, encoding trehalose-6-phosphate synthase. Plant J. 13:685-89

12. Blee KA, Anderson AJ. 1999. Regulation of arbuscule formation by carbon in the plant. Plant J. 16:523-30

13. Borisjuk L, Walenta S, Weber H, MuellerKlieser W, Wobus U. 1998. High-resolution histographical mapping of glucose concentrations in developing cotyledons of Vicia faba in relation to mitotic activity and storage processes: glucose as a possible developmental trigger. Plant J. 15:58391

14. Bouly J-P, Gissot L, Lessard P, Kreis M, Thomas M. 1999. Arabidopsis thaliana proteins related to the yeast SIP and SNF4 interact with $\mathrm{AKIN} \alpha 1$ : an SNF1-like protein kinase. Plant J. 18:541-50

15. Boxall S, Martin T, Graham IA. 1996. A new class of Arabidopsis mutants that is carbohydrate insensitive. Int. Conf. Arabidopsis Res., 7th, Norwich, UK. (Abstr.)

16. Braun DM, Stone JM, Walker JC. 1997. Interaction of the maize and Arabidopsis kinase interacting domains with a subset of receptor-like protein kinases: implications for transmembrane signaling in plants. Plant J. 12:83-95

17. Bustos MM, Iyer M, Gagliardi SJ. 1998. Induction of a $\beta$-phaseolin promoter by exogenous abscisic acid in tobacco: developmental regulation and modulation by external sucrose and $\mathrm{Ca}^{2+}$ ions. Plant Mol. Biol. 37:265-74

18. Carlson M. 1998. Regulation of glucose utilization in yeast. Curr. Opin. Genet. Dev. 8:560-64

19. Chan MT, Yu SM. 1998. The 3' untrans- lated region of a rice $\alpha$-amylase gene functions as a sugar-dependent mRNA stability determinant. Proc. Natl. Acad. Sci. USA 95:6543-47

20. Chan MT, Yu SM. 1998. The $3^{\prime}$ untranslated region of a rice $\alpha$-amylase gene mediates sugar-dependent abundance of mRNA. Plant J. 15:685-95

21. Chang YC, Walling LL. 1991. Abscisic acid negatively regulates expression of chlorophyll $a / b$ binding protein genes during soybean embryogeny. Plant Physiol. 97:1260-64

22. Cheng W, Tallercio EW, Chourey PS. 1996. The miniature1 seed locus of maize encodes a cell wall invertase required for normal development of endosperm and maternal cells in the pedicel. Plant Cell 8:971-83

23. Chiou TJ, Bush DR. 1998. Sucrose is a signal molecule in assimilate partitioning. Proc. Natl. Acad. Sci. USA 95:4784-88

24. Cutler S, Ghassemian M, Bonetta D, Cooney S, McCourt P. 1996. A protein farnesyl transferase involved in abscisic acid signal transduction in Arabidopsis. Science 273:1239-41

25. Dai N, Schaffer A, Petreikov M, Shahak Y, Giller Y, et al. 1999. Overexpression of Arabidopsis hexokinase in tomato plants inhibits growth, reduces photosynthesis, and induces rapid senescence. Plant Cell 11:1253-66

26. Davies JP, Yildiz FH, Grossman AR. 1999. Sac3: an Snf1-like serine/threonine kinase that positively and negatively regulates the responses of Chlamydomonas to sulfur limitation. Plant Cell 11:1179-90

27. De Bellis L, Ismail I, Reynolds SJ, Barrett MD, Smith SM. 1997. Distinct cis-acting sequences are required for the germination and sugar responses of the cucumber isocitrate lyase gene. Gene 197:375-78

28. de Bruijn SM, Ooms JJJ, Karssen CM, Vreugdenhil D. 1997. Effects of abscisic acid on reserve deposition in developing Arabidopsis seeds. Acta Bot. Neerl. 46:263-77 
29. De Vit MJ, Waddle JA, Johnston M. 1997. Regulated nuclear translocation of the Mig1 glucose repressor. Mol. Biol. Cell 8:1603-18

30. Dijkwel PP, Huijser, C, Weisbeek PJ, Chua N-H, Smeekens SCM. 1997. Sucrose control of phytochrome A signalling in Arabidopsis. Plant Cell 9:583-95

31. Dijkwel PP, Kock P, Bezemer R, Weisbeek P, Smeekens SCM. 1996. Sucrose represses the developmentally controlled transient activation of the plastocyanin gene in Arabidopsis thaliana seedlings. Plant Physiol. 110:455-63

32. Donggiun K, Laby RJ, Gibson SI. 1998. Regulation of sugar responses and characterization of Arabidopsis thaliana mutants with reduced beta-amylase activity. Int. Conf. Arabidopsis Res., Madison, WI, 9th. (Abstr.)

33. Douglas P, Moorhead G, Hong Y, Morrice N, MacKintosh C. 1998. Purification of a nitrate reductase kinase from Spinacea oleracea leaves, and its identification as a calmodulin-domain protein kinase. Planta 206:435-42

34. Douglas P, Pigaglio E, Ferrer A, Halfords NG, MacKintosh C. 1997. Three spinach leaf nitrate reductase-3-hydroxy3-methylglutaryl-CoA reductase kinases that are required by reversible phosphorylation and/or $\mathrm{Ca}^{2+}$ ions. Biochem. J. 325:101-9

35. Ehness R, Ecker M, Godt DE, Roitsch TH. 1997. Glucose and stress independently regulate source and sink metabolism and defence mechanisms via signal transduction pathways involving protein phosphorylation. Plant Cell 9:1825-41

36. Epstein PN, Boschero AC, Atwater I, Cai X, Overbeek PA. 1992. Expression of yeast hexokinase in pancreatic $\beta$ cells of transgenic mice reduces blood glucose, enhances insulin secretion, and decreases diabetes. Proc. Natl. Acad. Sci. USA 89:12038-42

37. Finkelstein RR, Wang ML, Lynch TJ, Rao
S, Goodman HM. 1998. The Arabidopsis abscisic acid response locus $A B I 4$ encodes an APETALA 2 domain protein. Plant Cell 10:1043-54

38. Focks N, Benning C. 1998. wrinkled1: A novel, low-seed-oil mutant of Arabidopsis with a deficiency in the seed-specific regulation of carbohydrate metabolism. Plant Physiol. 118:91-101

39. Fu H, Kim SY, Park WD. 1995. High-level tuber expression and sucrose inducibility of a potato Sus 4 sucrose synthase gene require $5^{\prime}$ and $3^{\prime}$ flanking sequences and the leader intron. Plant Cell 7:1387-94

40. Gancedo JM. 1998. Yeast carbon catabolite repression. Microbiol. Mol. Biol. Rev. 62:334-61

41. Garciarrubio A, Legaria JP, Covarrubias AA. 1997. Abscisic acid inhibits germination of mature Arabidopsis seeds by limiting the availability of energy and nutrients. Planta 203:182-87

42. Gibson SI, Graham IA. 1999. Another player joins the complex field of sugarregulated gene expression in plants. Proc. Natl. Acad. Sci. USA 96:4746-48

43. Gibson SI, Laby RJ, Donggiun K. 1999. Sugar-insensitive mutants of Arabidopsis with defects in phytohormone metabolism and/or response. Int. Conf. Arabidopsis Res., 10th, Melbourne, Aust., (Abstr.)

44. Goddijn O, Smeekens SCM. 1998. Sensing trehalose biosynthesis in plants. Plant J. 14:143-46

45. Goddijn OJ, Van Dun K. 1999. Trehalose metabolism in plants. Trends Plant Sci. 4:315-19

46. Godt DE, Riegel A, Roitsch T. 1995. Regulation of sucrose synthase expression in Chenopodium rubrum: characterization of sugar induced expression in photoautotrophic suspension cultures and sink tissue specific expression in plants. Plant Physiol. 146:231-38

47. Graham IA. 1996. Carbohydrate control of gene expression in higher plants. Res. Microbiol. 147:572-80 
48. Graham IA, Baker CJ, Leaver CJ. 1994. Analysis of the cucumber malate synthase gene promoter by transient expression and gel retardation assays. Plant J. 6:893-902

49. Graham IA, Denby KJ, Leaver CJ. 1994. Carbon catabolite repression regulates glyoxylate cycle gene-expression in cucumber. Plant Cell 6:761-72

50. Grierson C, Du J-S, de Torres Zabala M, Beggs K, Smith C, et al. 1994. Separate cis sequences and trans factors direct metabolic and developmental regulation of a potato tuber storage protein gene. Plant J. 5:815-26

51. Grupe A, Hultgren B, Ryan A, Ma YH, Bauer M, Stewart TA. 1995. Transgenic knockouts reveal a critical requirement for pancreatic $\beta$ cell glucokinase in maintaining glucose homeostasis. Cell 83:69-78

52. Gubler F, Jacobsen JV. 1992. Gibberellinresponsive elements in the promotor of a barley high-pI $\alpha$-amylase gene. Plant Cell $4: 1435-41$

53. Halford NG, Hardie DG. 1998. SNF1related protein kinases: global regulators of carbon metabolism in plants? Plant Mol. Biol. 37:735-48

54. Halford NG, Purcell P, Hardie DG. 1999. Is hexokinase really a sugar sensor in plants? Trends Plant Sci. 4:117-20

55. Hardie DG, Carling D. 1997. The AMPactivated protein kinase-fuel gauge of the mammalian cell? Eur. J. Biochem. 246:259-73

56. Hardie DG, Carling D, Carlson $M$. 1998. The AMP-activated/SNF1 protein kinase subfamily: metabolic sensors of the eukaryotic cell? Annu. Rev. Biochem. 67:821-55

57. Hare PD, Cress WA, van Staden J. 1998. Dissecting the roles of osmolyte accumulation during stress. Plant Cell Environ. 21:535-54

58. Herbers K, Meuwly P, Frommer W, Métraux J-P, Sonnewald U. 1996. Systemic acquired resistance mediated by the ectopic expression of invertase: possible hex- ose sensing in the secretory pathway. Plant Cell 8:793-803

59. Herrero P, Martinez-Campa C, Moreno F. 1998. The hexokinase 2 protein participates in regulatory DNA-protein complexes necessary for glucose repression of the SUC2 gene in Saccharomyces cerevisiae. FEBS Lett. 434:71-76

60. Hilgarth C, Sauer N, Tanner W. 1991. Glucose increases the expression of the ATP/ADP translocator and the glyceraldehyde-3-phosphate dehydrogenase genes in Chlorella. J. Biol. Chem. 266:24044-47

61. Hohmann S, Winderickx J, de Winde WH, Valckx D, Cobbaert P, et al. 1999. Novel alleles of yeast hexokinase PII with distinct effects on catalytic activity and catabolite repression of SUC2. Microbiology 145:703-14

62. Holmstrom KO, Mantyla E, Welin B, Mandal A, Palva ET. 1996. Drought tolerance in tobacco. Nature 379:683-84

63. Hong Y, Takano M, Liu CM, Gasch A, Chye ML, Chua NH. 1996. Expression of three members of the calcium-dependent protein kinase gene family in Arabidopsis thaliana. Plant Mol. Biol. 30:1259-75

64. Hrabak EM, Dickmann LJ, Satterlee JS, Sussman MR. 1996. Characterization of eight new members of the calmodulin-like domain protein kinase gene family from Arabidopsis thaliana. Plant Mol. Biol. 31:405-12

65. Hsiao AI, Quick WA. 1997. Roles of soluble sugars in protecting phytochrome- and gibberellin A3-mediated germination control in skotodormant lettuce seeds. J. Plant Growth Regul. 16:141-46

66. Hua J, Meyerowitz EM. 1998. Ethylene responses are negatively regulated by a receptor gene family in Arabidopsis thaliana. Cell 94:261-71

67. Huber SC, Huber JL, Liao PC, Gage DA, McMichael RW Jr, et al. 1996. Phosphorylation of serine-15 of maize leaf sucrose synthase. Occurrence in vivo and 
possible regulatory significance. Plant Physiol. 112:793-802

68. Huijser C, Kortstee A, Pego JV, Wisman E, Weisbeek P, Smeekens SCM. 1999. The Arabidopsis SUN6 gene is identical to ABI4. Submitted

69. Hwang YS, Karrer EE, Thomas BR, Chen L, Rodriguez RL. 1998. Three cis-elements required for rice $\alpha$-amylase Amy3D expression during sugar starvation. Plant Mol. Biol. 36:331-41

70. Ishiguro S, Nakamura, K. 1992. The nuclear factor SP8BF binds to the $5^{\prime}$-upstream regions of three different genes coding for major proteins of sweet potato tuberous roots. Plant Mol. Biol. 18:97-108

71. Ishiguro S, Nakamura K. 1994. Characterization of a cDNA encoding a novel DNA-binding protein, SPF1, that recognizes SP8 sequences in the $5^{\prime}$ upstream regions of genes coding for sporamin and $\alpha$-amylase from sweet potato. Mol. Gen. Genet. 244:563-71

72. Jackson SD, Heyer A, Dietze J, Prat S. 1996. Phytochrome B mediates the photoperiodic control of tuber formation in potato. Plant J. 9:159-66

73. Jang J-C, Leon P, Zhou L, Sheen J. 1997. Hexokinase as a sugar sensor in higher plants. Plant Cell 9:5-19

74. Jang J-C, Sheen J. 1997. Sugar sensing in higher plants. Trends Plant Sci. 2:208-14

75. Jang JC, Sheen J. 1994. Sugar sensing in higher plants. Plant Cell 6:1665-79

76. Jefferson R, Goldsbrough A, Bevan M. 1990. Transcriptional regulation of a patatin-1 gene in potato. Plant Mol. Biol. 14:995-1006

77. Jiang R, Carlson M. 1996. Glucose regulates protein interactions within the yeast SNF1 protein kinase complex. Genes Dev. 10:3105-15

78. Jitla D, Rogers G, Seneweera S, Basra A, Oldfield R, Conroy J. 1997. Accelerated early growth of rice at elevated $\mathrm{CO}_{2}$. Plant Physiol. 115:15-22

79. Johnston M. 1999. Feasting, fasting and fermenting. Glucose sensing in yeast and other cells. Trends Genet. 15:29-33

80. Kaiser WM, Huber SC. 1994. Modulation of nitrate reductase in vivo and in vitro: effects of phosphoprotein phosphatase inhibitors, free $\mathrm{Mg}^{2+}$ and $5^{\prime}$ AMP. Planta 193:358-64

81. Kaplan CP, Tugal HB, Baker A. 1997. Isolation of a cDNA encoding an Arabidopsis galactokinase by functional expression in yeast. Plant Mol. Biol. 34:497-506

82. Karrer EE, Rodriguez RL. 1992. Metabolic regulation of rice $\alpha$-amylase and sucrose synthase genes in planta. Plant J. 2:517-23

83. Kemp BE, Mitchelhill KI, Stapleton D, Michell BJ, Chen ZP, Witters LA. 1999. Dealing with energy demand: the AMPactivated protein kinase. Trends Biochem. Sci. 24:22-25

84. Kim D-J, Smith SM, Leaver CJ. 1997. A cDNA encoding a putative SPF1type DNA-binding protein from cucumber. Gene 185:265-69

85. Kim SY, May GD, Park WD. 1994. Nuclear protein factors binding to a class I patatin promoter region are tuber-specific and sucrose-inducible. Plant Mol. Biol. 26:603-15

86. Kinsman E, Lewis C, Davies M, Young J, Francis D, et al. 1997. Elevated $\mathrm{CO}_{2}$ stimulates cells to divide in grass meristems: a differential effect in two natural populations of Dactylis glomerata. Plant Cell Environ. 20:1309-16

87. Klein D, Stitt M. 1998. Effects of 2deoxyglucose on the expression of RBCS and the metabolism of Chenopodium rubrum cell suspension cultures. Planta 205:223-34

88. Koch KE. 1996. Carbohydrate-modulated gene expression in plants. Annu. Rev. Plant Physiol.Plant Mol. Biol. 47:509-40

89. Kraakman L, Lemaire K, Ma P, Teunissen AWRH, Donaton M, et al. 1999. A Saccharomyces cerevisiae G-coupled receptor, Gpr1, is specifically required for glucose activation of the cAMP pathway during the 
transition to growth on glucose. Mol. Microbiol. 32:1002-12

90. Kraakman LS, Winderickx J, Thevelein JM, de Winde JH. 1999. Structure-function analysis of yeast hexokinase: structural requirements for triggering cAMP signalling and catabolite repression. Biochem. J. 343:159-68

91. Krapp A, Hofmann B, Schafer C, Stitt M. 1993. Regulation of expression of $r b c S$ and other photosynthetic genes by carbohydrates: a mechanism for the 'sink regulation' of photosynthesis? Plant J. 3:817-28

92. Kusnetsov V, Herrmann RG, Kulaeva ON, Oelmuller R. 1998. Cytokinin stimulates and abscisic acid inhibits greening of etiolated Lupinus luteus cotyledons by affecting the expression of the light-sensitive protochlorophyllide oxidoreductase. Mol. Gen. Genet. 259:21-28

93. Lakatos L, Klein M, Hofgen R, Banfalvi Z. 1999. Potato StubSNF1 interacts with StubGAL83: a plant protein kinase complex with yeast and mammalian counterparts. Plant J. 17:569-74

94. Lalonde S, Boles E, Hellmann H, Barker L, Patrick JW, et al. 1999. The dual function of sugar carriers. Transport and sugar sensing. Plant Cell 11:707-26

95. Lam H-M, Coschigano KT, Oliveira IC, Melo-Oliveira R, Coruzzi GM. 1996. The molecular-genetics of nitrogen assimilation into amino acids in higher plants. Annu. Rev. Plant Physiol. Plant Mol. Biol. 47:569-93

96. Levy YY, Dean C. 1998. The transition to flowering. Plant Cell 10:1973-90

97. Liu XJ, Prat S, Willmitzer L, Frommer WB. 1990. Cis regulatory elements directing tuber-specific and sucrose-inducible expression of a chimeric class I patatin promoter/GUS-gene fusion. Mol. Gen. Genet. 23:401-6

98. Lucas WJ, Wolf S. 1999. Connections between virus movement, macromolecular signaling and assimilate allocation. Curr. Opin. Plant Biol. 2:192-97
99. Lue M-Y, Lee H. 1994. Protein phosphatase inhibitors enhance the expression of an $\alpha$-amylase gene, $\alpha$ Amy3, in cultured rice cells. Biochem. Biophys. Res. Commun. 205:807-16

100. MacKintosh C. 1998. Regulation of cytosolic enzymes in primary metabolism by reversible protein phosphorylation. Curr. Opin. Plant Biol. 1:224-29

101. Martin T, Hellmann H, Schmidt R, Willmitzer L, Frommer WB. 1997. Identification of mutants in metabolically regulated gene expression. Plant J. 11:53-62

102. Matschinsky F, Liang Y, Kesavan P, Wang L. 1993. Glucokinase as pancreatic $\beta$ cell glucose sensor and diabetes gene. J. Clin. Invest. 92:2092-98

103. Medford JI, Sussex IM. 1989. Regulation of chlorophyll and Rubisco levels in embryonic cotyledons of Phaseolus vulgaris. Planta 179:309-15

104. Mita S, Hirano H, Nakamura K. 1997. Negative regulation in the expression of a sugar-inducible gene in Arabidopsis thaliana; a recessive mutation causing enhanced expression of a gene for $\beta$ amylase. Plant Physiol. 114:575-82

105. Mita S, Murano N, Akaike M, Nakamura K. 1997. Mutants of Arabidopsis thaliana with pleiotropic effects on the expression of the gene for $\beta$-amylase and on the accumulation of anthocyanin that are inducible by sugars. Plant $J$. 11:841-51

106. Mita S, Suzuki-Fujii K, Nakamura K. 1995. Sugar-inducible expression of a gene for $\beta$-amylase in Arabidopsis thaliana. Plant Physiol. 107:895-904

107. Moore BD, Sheen J. 1999. Plant sugar sensing and signaling - a complex reality. Trends Plant Sci. 4:250

108. Moorhead G, Douglas P, Cotelle V, Harthill J, Morrice N, et al. 1999. Phosphorylation-dependent interactions between enzymes of plant metabolism and 14-3-3 proteins. Plant J. 18:1-12

109. Morita A, Umemura T, Kuroyanagi M, Futsuhara Y, Perata P, Yamaguchi J. 1998. 
Functional dissection of a sugar-repressed $\alpha$-amylase gene (RAmy1 A) promoter in rice embryos. FEBS Lett. 423:81-85

110. Müller J, Boller T, Wiemken A. 1998. Trehalose affects sucrose synthase and invertase activities in soybean (Glycine max $\mathrm{L}$. Merr.) roots. J. Plant Physiol. 153:255-57

111. Nemeth K, Salchert K, Putnoky P, Bhalerao R, Koncz-Kalman Z, et al. 1998. Pleiotropic control of glucose and hormone responses by PRL1: a nuclear WD protein, in Arabidopsis. Genes Dev. 12:3059-73

112. Nielsen TH, Krapp A, Roeper-Schwarz U, Stitt M. 1998. The sugar-mediated regulation of genes encoding the small subunit of Rubisco and the regulatory subunit of ADP glucose pyrophosphorylase is modified by phosphate and nitrogen. Plant Cell Environ. 21:443-54

113. Ohto M, Hayashi K, Isobe M, Nakamura K. 1995. Involvement of $\mathrm{Ca}^{2+}$-signalling in the sugar-inducible expression of genes coding for sporamin and $\beta$-amylase of sweet potato. Plant J. 7:297-307

114. Ohto M, Nakamura-Kito K, Nakamura K. 1992. Induction of expression of genes coding for sporamin and $\beta$-amylase by polygalacturonic acid in leaf-petiole cuttings of sweet potato. Plant Physiol. 99:422-27

115. Ohto M, Nakamura K. 1995. Sugarinduced increase of calcium-dependent protein kinases associated with the plasma membrane in leaf tissues of tobacco. Plant Physiol. 109:973-81

116. Özcan S, Dover J, Johnston M. 1998. Glucose sensing and signaling by two glucose receptors in the yeast Saccharomyces cerevisiae. EMBO J. 17:2566-73

117. Özcan S, Dover J, Rosenwald AG, Wolfl S, Johnston M. 1996. Two glucose transporters in Saccharomyces cerevisiae are glucose sensors that generate a signal for induction of gene expression. Proc. Natl. Acad. Sci. USA 93:1-5

118. Paul MJ, Driscoll SP. 1997. Sugar re- pression of photosynthesis: the role of carbohydrates in signalling nitrogen deficiency through source:sink imbalance. Plant Cell Environ. 20:110-16

119. Pego JV, Kortstee A, Huijser C, Smeekens SCM. 2000. Photosynthesis, sugars and the regulation of gene expression. J. Exp. Bot. 51:407-16

120. Pego JV, Krapp A, Wobbes B, Weisbeek P, Stitt M, Smeekens SCM. 2000. Arabidopsis fructokinase 2 and its involvement in metabolite-mediated regulation of gene expression. Submitted

121. Pego JV, Weisbeek PJ, Smeekens SCM. 1999. Mannose inhibits Arabidopsis germination via a hexokinase-mediated step. Plant Physiol. 119:1017-23

122. Perata P, Matsukura C, Vernieri P, Yamaguchi J. 1997. Sugar repression of a gibberellin-dependent signaling pathway in barley embryos. Plant Cell 9:2197-208

123. Platt A, Reece RJ. 1998. The yeast galactose genetic switch is mediated by the formation of a Gal4p-Gal80p-Gal3p complex. EMBO J, 17:4086-91

124. Prata RTN, Williamson JD, Conkling MA, Pharr DM. 1997. Sugar repression of mannitol dehydrogenase activity in celery cells. Plant Physiol. 114:307-14

125. Purcell PC, Smith AM, Halford NG. 1998. Antisense expression of a sucrose non-fermenting-1-related protein kinase sequence in potato results in decreased expression of sucrose synthase in tubers and loss of sucrose-inducibility of sucrose synthase transcripts in leaves. Plant J. 14:195-202

126. Reynolds SJ, Smith SM. 1995. Regulation of expression of the cucumber isocitrate lyase gene in cotyledons upon seed germination and by sucrose. Plant Mol. Biol. 29:885-96

127. Riou-Khamlichi C, Huntley R, Jacqmard A, Murray JA. 1999. Cytokinin activation of Arabidopsis cell division through a D-type cyclin. Science 283:1541-44

128. Robertson M, Swain SM, Chandler PM, 
Olszewski NE. 1998. Identification of a negative regulator of gibberellin action, HvSPY, in barley. Plant Cell 10:9951007

129. Robinson CK, Hill SA. 1999. Altered resource allocation during seed development in Arabidopsis by the abi3 mutation. Plant Cell Environ. 22:117-23

130. Rogers JC, Rogers SW. 1992. Definition and functional implications of gibberellin and abscisic acid cis-acting hormone response complexes. Plant Cell 4:1443-51

131. Rohde A, van Montagu M, Boerjan W. 1999. The ABSCISIC ACIDINSENSITIVE $3(A B I 3)$ gene is expressed during vegetative quiescence processes in Arabidopsis. Plant Cell Environ. 22:26170

132. Roitsch T. 1999. Source-sink regulation by sugar and stress. Curr. Opin. Plant Biol. 2:198-206

133. Roitsch T, Bittner M, Godt DE. 1995. Induction of apoplastic invertase of Chenopodium rubrum by D-glucose and a glucose analog and tissue-specific expression suggest a role in sink-source regulation. Plant Physiol. 108:285-94

134. Romero C, Bellés JM, Vayaz JL, Serrano R, Culianez-Macià FA. 1997. Expression of the yeast trehalose-6-phosphate synthase gene in transgenic tobacco plants: pleiotropic phenotypes include drought tolerance. Planta 201:293-97

135. Rook F, Gerrits N, Kortstee A, van Kampe M, Borrias M, et al. 1998. Sucrosespecific signalling represses translation of the Arabidopsis ATB2 bZIP transcription factor gene. Plant J. 15:253-63

136. Rook F, Weisbeek PJ, Smeekens SCM. 1998. The light-controlled Arabidopsis bZIP transcription factor gene ATB2 encodes a protein with an unusually long leucine zipper domain. Plant Mol. Biol. 37:171-78

137. Sadka A, DeWald DB, May GD, Park WD, Mullet JE. 1994. Phosphate modulates transcription of soybean $V s p B$ and other sugar inducible genes. Plant Cell 6:737-49

138. Salchert K, Bhalerao R, Koncz-Kalman Z, Koncz C. 1998. Control of cell elongation and stress responses by steroid hormones and carbon catabolic repression in plants. Philos. Trans. R. Soc. London Ser. B 353:1517-20

139. Salzman RA, Tikhonova I, Bordelon BP, Hasegawa PM, Bressan RA. 1998. Coordinate accumulation of antifungal proteins and hexoses constitutes a developmentally controlled defense response during fruit ripening in grape. Plant Physiol. 117:465-72

140. Sarah CJ, Graham IA, Reynolds SJ, Leaver CJ, Smith SM. 1996. Distinct cis-acting elements direct the germination and sugar responses of the cucumber malate synthase gene. Mol. Gen. Genet. 250:153-61

141. Scheible W-R, Gonzalez-Fontez A, Lauerer M, Müller-Röber B, Caboche M, Stitt M. 1997. Nitrate acts as a signal to induce organic acid metabolism and repress starch metabolism in tobacco. Plant Cell 9:809-24

142. Sharkey TD, Vassey TL, Vanderveer PJ, Vierstra RD. 1991. Carbon metabolism and photosynthesis in transgenic tobacco (Nicotiana tabacum L.) having excess phytochrome. Planta 185:287-96

143. Sharma R, Schopfer P. 1987. Phytochrome-mediated regulation of $\beta$-amylase mRNA level in mustard (Sinapsis alba L.) cotyledons. Planta 171:31320

144. Sheen J. 1990. Metabolic repression of transcription in higher plants. Plant Cell 2:1027-38

145. Sherson S, Gy I, Medd J, Schmidt R, Dean C, et al. 1999. The arabinose kinase, $A R A 1$, gene of Arabidopsis is a novel member of the galactose kinase gene family. Plant Mol. Biol. 39:1003-12

146. Sheu J, Jan S, Lee H, Yu S. 1994. Control of transcription and mRNA turnover as 
mechanisms of metabolic repression of $\alpha$ amylase gene expression. Plant J. 5:65564

147. Short TW. 1999. Overexpression of Arabidopsis phytochrome B inhibits phytochrome A function in the presence of sucrose. Plant Physiol. 119:1497-506

148. Sims DA, Luo Y, Seemann JR. 1998. Importance of leaf versus whole plant $\mathrm{CO}_{2}$ environment for photosynthetic acclimation. Plant Cell Environ. 21:1189-96

149. Smeekens SCM. 1998. Sugar regulation of gene expression in plants. Curr. Opin. Plant Biol. 1:230-34

150. Smeekens SCM, Rook F. 1997. Sugar sensing and sugar-mediated signal transduction in plants. Plant Physiol. 115:7-13

151. Soni R, Carmichael JP, Shah ZH, Murray JA. 1995. A family of cyclin D homologs from plants differentially controlled by growth regulators and containing the conserved retinoblastoma protein interaction motif. Plant Cell 7:85-103

152. Stitt M. 1999. Nitrate regulation of metabolism and growth. Curr. Opin. Plant Biol. 2:178-86

153. Sugden C, Donaghy PG, Halford NG, Hardie DG. 1999. Two SNF1-related protein kinases from spinach leaf phosphorylate and inactivate 3-hydroxy-3methylglutaryl-coenzyme A reductase, nitrate reductase, and sucrose phosphate synthase in vitro. Plant Physiol. 120:25774

154. Takeda S, Mano S, Ohto M, Nakamura K. 1994. Inhibitors of protein phosphatases I and 2A block the sugarinducible gene expression in plants. Plant Physiol. 106:567-74

155. Tang GQ, Luscher M, Sturm A. 1999. Antisense repression of vacuolar and cell wall invertase in transgenic carrot alters early plant development and sucrose partitioning. Plant Cell 11:177-89

156. Tegeder M, Wang XD, Frommer WB, Offler CE, Patrick JW. 1999. Sucrose transport into developing seeds of Pisum sativum L. Plant J. 18:151-61

157. Thevelein JM, Hohmann S. 1995. Trehalose synthase: guard to the gate of glycolysis in yeast? Trends Biochem Sci. 20:3-10

158. Thiele A, Herold M, Lenk I, Quail PH, Gatz C. 1999. Heterologous expression of arabidopsis phytochrome B in transgenic potato influences photosynthetic performance and tuber development. Plant Physiol. 120:73-82

159. Thomas BR, Rodriguez RL. 1994. Metabolite signals regulate gene expression and source/sink relations in cereal seedlings. Plant Physiol. 106:1235-39

160. Thomashow MF. 1999. Plant cold acclimation: freezing tolerance genes and regulatory mechanisms. Annu. Rev. Plant Physiol. Plant Mol. Biol. 50:571-99

161. Toroser D, Huber SC. 1997. Protein phosphorylation as a mechanism for osmoticstress activation of sucrose-phosphate synthase in spinach leaves. Plant Physiol. 114:947-55

162. Toroser D, Huber SC. 1998. 3-Hydroxy3-methylglutaryl-coenzyme A reductase kinase and sucrose-phosphate synthase kinase activities in cauliflower florets: $\mathrm{Ca}^{2+}$ dependence and substrate specificities. Arch. Biochem. Biophys. 355:291300

163. Treitel MA, Carlson M. 1995. Repression by SSN6-TUP1 is directed by MIG1: a repressor/activator protein. Proc. Natl. Acad. Sci. USA 92:3132-36

164. Treitel MA, Kuchin S, Carlson M. 1998. Snf1 protein kinase regulates phosphorylation of the Mig1 repressor in Saccharomyces cerevisiae. Mol. Cell. Biol. 18:6273-80

165. Umemura $\mathrm{T}$, Perata $\mathrm{P}$, Futsuhara $\mathrm{Y}$, Yamaguchi J. 1998. Sugar sensing and $\alpha$ amylase gene repression in rice embryos. Planta 204:420-28

166. van Oosten JJ, Gerbaud A, Huijser C, Dijkwel PP, Chua N-H, Smeekens SCM. 1997. An Arabidopsis mutant showing 
reduced feedback inhibition of photosynthesis. Plant J. 12:1011-20

167. Vogel G, Aeschbacher RA, Müller J, Boller T, Wiemken A. 1998. Trehalose6-phosphate phosphatases from Arabidopsis thaliana: identification by functional complementation of the yeast tps 2 mutant. Plant J. 13:673-83

168. Vreugdenhil D. 1983. Abscisic acid inhibits phloem loading of sucrose. Physiol. Plant. 57:463-67

169. Wanner LA, Junttila O. 1999. Coldinduced freezing tolerance in Arabidopsis. Plant Physiol. 120:391-99

170. Weatherwax SC, Ong MS, Degenhardt J, Bray EA, Tobin EM. 1996. The interaction of light and abscisic acid in the regulation of plant gene expression. Plant Physiol. 111:363-70

171. Weatherwax SC, Williams SA, Tingay S, Tobin EM. 1998. The phytochrome response of the Lemna gibba NPR1 gene is mediated primarily through changes in abscisic acid levels. Plant Physiol. 116:1299-305

172. Weber H, Borisjuk L, Heim U, Sauer N, Wobus U. 1997. A role for sugar transporters during seed development: molecular characterization of a hexose and a sucrose carrier in fava bean seeds. Plant Cell 9:895-908

173. Weber H, Borisjuk L, Wobus U. 1996. Controlling seed development and seed size in Vicia faba: a role for seed coatassociated invertases and carbohydrate state. Plant J. 10:823-34

174. Weber H, Buchner P, Borisjuk L, Wobus U. 1996. Sucrose metabolism during cotyledon development of Vicia faba L. is controlled by the concerted action of both sucrose-phosphate synthase and sucrose synthase: expression patterns, metabolic regulation and implications for seed development. Plant J. 9:841-50

175. Weber H, Heim U, Golombek S, Borisjuk L, Manteuffel R, Wobus U. 1998. Expression of a yeast-derived invertase in de- veloping cotyledons of Vicia narbonensis alters the carbohydrate state and affects storage functions. Plant J. 16:163-72

176. Weber H, Wobus U. 1997. Sugar import and metabolism during seed development. Trends Plant Sci. 2:169-74

177. Wenzler HC, Mignery G, Fisher L, Park W. 1989. Sucrose-regulated expression of a chimeric potato tuber gene in leaves of transgenic tobacco plants. Plant Mol. Biol. 13:347-54

178. Whitelam GC, Johnson E, Peng J, Carol $\mathrm{P}$, Anderson ML, et al.1993. Phytochrome A null mutants of Arabidopsis display a wild-type phenotype in white light. Plant Cell 5:757-68

179. Williams RW, Wilson JM, Meyerowitz EM. 1997. A possible role for kinaseassociated protein phosphatase in the Arabidopsis CLAVATA1 signaling pathway. Proc. Natl. Acad. Sci. USA 94:10467-72

180. Wobus U, Weber H. 1999. Seed maturation: genetic programmes and control signals. Curr. Opin. Plant Biol. 2:33-38

181. Wu K, Rooney MF, Ferl RJ. 1997. The Arabidopsis 14-3-3 multigene family. Plant Physiol. 114:1421-31

182. Xu X, van Lammeren AA, Vermeer E, Vreugdenhil D. 1998. The role of gibberellin, abscisic acid, and sucrose in the regulation of potato tuber formation in vitro. Plant Physiol. 117:575-84

183. Yanovsky MJ, Alconada-Magliano TM, Mazzella MA, Gatz C, Thomas B, Casal JJ. 1998. Phytochrome A affects stem growth, anthocyanin synthesis, sucrosephosphate-synthase activity and neighbour detection in sunlight-grown potato. Planta 205:235-41

184. Yokoyama R, Hirose T, Fujii N, Aspuria ET, Kato A, Uchimiya H. 1994. The rolC promoter of Agrobacterium rhizogenes Ri plasmid is activated by sucrose in transgenic tobacco plants. Mol. Gen. Genet. 244:15-22

185. Yu SM, Kuo YH, Sheu G, Sheu YJ, Liu LF. 1991. Metabolic derepression of 
$\alpha$-amylase gene expression in suspension-cultured cells of rice. J. Biol. Chem. 266:21131-37

186. Zenke FT, Engles R, Vollenbroich V, Meyer J, Hollenberg CP, Breunig KD. 1996. Activation of Gal4p by galactosedependent interaction of galactokinase and Gal80p. Science 272:1662-65 [erratum in Science 273:417]

187. Zhou D, Qian D, Cramer CL, Yang Z.
1997. Developmental and environmental regulation of tissue- and cell-specific expression for a pea protein farnesyltransferase gene in transgenic plants. Plant J. 12:921-30

188. Zhou L, Jang JC, Jones TL, Sheen J. 1998. Glucose and ethylene signal transduction crosstalk revealed by an Arabidopsis glucose-insensitive mutant. Proc. Natl. Acad. Sci. USA 95:10294-99 